\title{
GUÍAS ESQUEMATIZADAS DE TRATAMIENTO DE LOS TRASTORNOS DE LA PERSONALIDAD PARA PROFESIONALES, DESDE EL MODELO DE YOUNG, KLOSKO Y WHEISHAR (2003)
}

\section{SCHEMATIC-GUIDES FOR PROFESSIONALS TO TREAT PERSONALITY DISORDERS, FROM THE MODEL OF YOUNG, KLOSKO AND WHEISHAR (2003)}

\author{
Andrés Fernando López Pell \\ Universidad Católica de Santa Fe y FUNSALED, Argentina \\ Jordi Cid Colom \\ International Society of Schema Therapy \\ Julio Obst Camerini \\ UAI y C.A.T.R.E.C. \\ Juan M. Rondón \\ Universidad Católica de Santa Fe, Argentina \\ Silvina M. Alfano \\ Universidad Católica de Santa Fe, Argentina \\ Cecilia Cellerino \\ Universidad Católica de Santa Fe, Argentina
}

\begin{abstract}
Resumen: Los tratamientos psicológicos para Trastornos de la personalidad todavía no alcanzan un grado de protocololarización específico como para describir las intervenciones para cada sesión. Esto podría deberse, entre otras cuestiones, a la heterogeneidad de los casos que dificultaría la posibilidad de diseñar un protocolo. Los tratamientos entonces se basan en conceptualizaciones de caso sustentadas teóricamente que después determinan los objetivos y las intervenciones a realizar. La dificultad para conceptualizar desde determinado modelo puede que sea una razón por la que a los psicoterapeutas les costaría realizar el tratamiento más adecuado. Para afrontar este problema hemos construido 'Guías esquematizadas para profesionales’ para mejorar la práctica clínica. Estas guías son de una carilla para tenerlas a la vista durante las sesiones a fin conceptualizar los casos y guiar más fácilmente las intervenciones desde el modelo de Young, Klosko y Wheishar (2003). Este artículo describe el proceso de construcción de las guías.
\end{abstract}

Palabras clave: personalidad, trastornos, tratamiento, terapia de esquemas.

\begin{abstract}
Psychological treatments for personality disorders have not yet reached a level of protocol as specific as to describe interventions for each session. This could be due, among other factors, to the heterogeneity of cases that make it difficult to design a protocol. Treatments are then based on case conceptualizations supported by theories that determine the objectives and interventions performed. The difficulty to conceptualize from a particular model may be a reason why psychotherapists find problems to make the most appropriate treatment. Addressing this problem, we have designed a set of 'Professional schematic-guides' to improve the clinical practice. These one-page-guides were created to have them in front of you during the sessions, and help to conceptualize cases and easily guide the interventions from the model of Young, Klosko y Wheishar (2003). This article describes the process of building guidelines.
\end{abstract}

Keywords: personality, disorders, treatment, schema therapy.

\section{INTRODUCCIÓN}

Nada ha demostrado ser más eficaz que la aplicación de un protocolo psicoterapéutico científicamente validado. Sin embargo ¿qué hacer cuando el paciente tiene varios trastornos?, o ¿cuándo no hay un protocolo validado para tratar el trastorno que sufre? En tales circunstancias, una opción es basar el tratamiento en una conceptualización de sus problemas guiada por un marco teórico. La dificultad para conceptualizar desde determinado modelo puede que sea una la las tantas razones del por qué a los psicoterapeutas les cueste más 
seguir las pautas descriptas para el abordaje de estas alteraciones. Otra cuestión de suma importancia es que son pacientes muy difíciles de mantener en tratamiento por lo cual se requiere de mucha flexibilidad por parte del terapeuta. Esto, sumado a la heterogeneidad de los casos, dificulta la posibilidad de diseñar un protocolo de tratamiento de alta especificidad delineado para cada sesión como existe para otros trastornos (e.g., depresivo mayor, de angustia, ansiedad generalizada, etc.) ya que cada tratamiento, si bien es guiado por la misma base teórica, termina adquiriendo una forma particular.

En busca de enfrentar la problemática planteada, en artículos anteriormente publicados en esta revista, propusieron el concepto de Guías esquematizadas para profesionales (López Pell, Rondón, Alfano, \& Cellerino, 2010; López Pell, Rondón, Cellerino \& Alfano, 2010). En aquella ocasión, las guías se hicieron para los modelos de Theodore Millon y de Beck, Freeman, Davis y otros (2005). En esta oportunidad, utilizando el mismo concepto, se realizarán para el modelo que vienen desarrollando Young, Klosko y Wheishar (2003).

Las Guías esquematizadas para profesionales están diseñadas para mejorar la práctica de la psicoterapia para los trastornos y alteraciones de la personalidad. Fueron realizadas en una carilla cada una con la idea que los psicoterapeutas las tengan a la vista durante las sesiones y que de esta manera puedan conceptualizar sus casos y guiar más fácilmente sus intervenciones. Atento a estas cuestiones, en este artículo se presentan los conceptos centrales que deben guiar la praxis desde el modelo de Young, Klosko y Wheishar (2003) de una manera simple y comprensible a fin de facilitar la transferencia del conocimiento al set psicoterapéutico.

\section{TEORÍA DE LA PERSONALIDAD}

Se ha desarrollado en los últimos años dentro del paradigma cognitivo conductual un modelo de abordaje terapéutico denominado Terapia de Esquemas (TE). Ésta es una forma de psicoterapia integrativa, que combina elementos cognitivos, conductuales, psicodinámicos, de las relaciones objetales y humanistas/existenciales (Young, Klosko \& Wheishar, 2003). Surge a partir de los conceptos teóricos desarrollados por Beck, especialmente en el área de los trastornos de personalidad, los esquemas, las estrategias y los modos (Alford \& Beck, 1997; Beck, 1996; Beck, Freeman, Davis y otros, 2005). La TE ha sido desarrollada por Jeffrey Young (1990; 1993) para tratar a pacientes que reciben un diagnóstico de trastornos de la personalidad o aquellos con problemas psicológicos que se consideran difíciles de tratar, porque suponen un reto desde la perspectiva del terapeuta. La TE se desarrolla para tratar problemas psicológicos graves, arraigados, de larga duración, y que presentan dificultades por generar y mantener la estabilidad sintomática, recaídas constantes, problemas interpersonales o rigidez de patrones conductuales (Young, 1993). Si bien inicialmente fue conceptualizada como una terapia para los Trastornos de la personalidad, en la actualidad se la utiliza y con eficacia para lo que en el DSM-IV TR serían los trastornos del Eje I (American Psychiatric Association, 2002), dentro de los cuales esta ansiedad, depresión, trastornos alimentarios.

Cuando presentó sus fundamentos Jeffrey Young consideró que el abordaje tradicional de la terapia cognitiva en ese momento no tenía un desarrollo suficientemente amplio y específico para los pacientes con trastornos de personalidad. Su argumento era que estos pacientes no cumplen con ciertos requisitos o supuestos del modelo clásico, debido a las siguientes cuestiones:

1. Dificultades en la identificación de sentimientos y cogniciones. Es bien conocido que las personas con problemas de personalidad bloquean sus emociones y pensamientos. Muchos tienen una tendencia afectiva de evitar las emociones.

2. Problemas para el cumplimiento de las tareas para casa. La colaboración y la motivación para trabajar entre sesión y sesión es difícil de obtener en los TP. Las tareas y/o deberes que se asignan habitualmente en la terapia se tornan de difícil seguimiento.

3. Imposibilidad de definir y clarificar los problemas de la vida. Presentan problemas difusos, vagos que no saben definir como objetivos del tratamiento.

4. Resistencias a una relación terapéutica colaboradora. No es tarea fácil aplicar ni encontrar el empirismo colaborador en el que se fundamenta la terapia cognitiva. Muestran dificultades en sus relaciones interpersonales, tienen problemas para tener una buena alianza terapéutica. En el 
tratamiento se va a necesitar manejar estas dificultades de manera activa.

5. Dificultades para modificar sus creencias rígidas. Las técnicas utilizadas en la terapia cognitiva, en muchos casos no son suficientes para cambiar los patrones autodestructivos y la rigidez de pensamientos. Las creencias y los patrones autodestructivos forman parte de la definición de la identidad de los pacientes con TP, muchas veces el cambio sólo es parcial.

\section{Conceptos básicos}

Para este modelo de abordaje, Young y Klosko (2007) definen una subcategoría de esquemas: Ios Esquemas Tempranos Inadaptados (ETI). Estos son patrones disfuncionales -auto-saboteadores- de pensamiento y emoción que se iniciaron en temprana edad y se reiteran a lo largo de la vida. Según esta definición, las conductas inadaptadas no son componentes de los esquemas, sino que son las respuestas a estos. Las conductas son causadas por los esquemas, pero no son parte de los mismos. Sin embargo, Cid (2009) prefiere denominarlos 'Esquemas Precoces Desadaptativos', definiéndolos como temas amplios y persistentes formados por recuerdos, emociones, pensamientos y sensaciones corporales que hacen referencia al análisis de uno mismo y de las relaciones con los demás. Estas se originan durante la infancia y se van elaborando a lo largo de la vida del individuo, siendo disfuncionales en grado significativo.

Los ETI se originan en representaciones basadas en la realidad y en su comienzo pueden generar respuestas adaptadas a éstas. Su disfuncionalidad se muestra más tarde en la vida, cuando esas percepciones o apreciaciones ya nos son ajustadas a la realidad. Los mecanismos humanos de supervivencia, en particular el impulso a la consistencia cognitiva -o a evitar la disonancia cognitiva-, generan la poderosa energía que los defiende ante todo intento de modificarlos, forzando a las otras percepciones a ajustarse a ellos (Young \& Klosko, 2007).

Pero estos esquemas pueden tener distintos grados de gravedad y de rigidez o resistencia al cambio. La gravedad puede definirse por la cantidad de situaciones que los activan. La mayor o menor severidad y resistencia al cambio dependerán de lo temprano -o tardío- de la edad en que se generaron, de la cantidad de figuras significativas que lo generaron y de la cantidad -o duración- de las situaciones que lo generaron. Por ejemplo, será más severo y rígido un esquema generado por ambos progenitores, desde la edad de 4 o 5 años y durante toda la infancia, que uno generado por un solo progenitor, o solamente por un maestro, en un episodio único, cuando tenía 12 años de edad (Young \& Klosko, 2007).

Podemos decir que hay esquemas positivos (i.e., adaptados) y negativos (i.e., inadaptados), así como tempranos y tardíos (Young, Klosko \& Wheishar, 2003). Pero al hablar de esquemas en este trabajo estaremos refiriéndonos específicamente a los esquemas tempranos e inadaptados -negativos- (ETI) por su relación causal con los trastornos de personalidad que queremos abordar.

En resumen, las características más relevantes de los ETI son las siguientes:

1. Son verdades a priori acerca de uno mismo y del ambiente, estructuras centrales del auto-concepto.

2. Se auto-perpetúan y son resistentes al cambio; es decir, no se modifican y se mantienen a lo largo del tiempo.

3. Son disfuncionales o desadaptativos: con consecuencias auto-destructivas y/o daño significativo para los demás. Interfieren de forma significativa en la satisfacción de las necesidades nucleares de autonomía, unión con los demás, auto-expresión, límites, gratificaciones y autoestima necesarias para una calidad de vida saludable.

4. Son activados por cambios ambientales relevantes al esquema o por estados de ánimo o estados biológicos. No siempre están en nuestra conciencia. Cuando se activan se acompañan de altos niveles de afecto o emociones.

5. Son el resultado de la interacción del temperamento con las experiencias nocivas o interacciones dolorosas y disfuncionales con los miembros de la familia o cuidadores en la infancia.

Finalmente, se nombrarán y describirán brevemente los 18 esquemas tempranos inadaptados propuestos por Young y Klosko (2007) que se relacionan con las necesidades básicas que se exponen más adelante, cuando estas no han sido satisfechas adecuadamente. Estos esquemas a su vez se agrupan, en cinco dimensiones o dominios (véase Tabla 4): 


\section{1) Desconexión y rechazo}

1. Abandono/Inestabilidad. La percepción de inestabilidad o de poca seguridad, de que se dispone de soporte y relación con los demás.

2. Desconfianza/Abuso. La expectativa de que los otros lo herirán, abusarán, humillarán, burlarán, mentirán, manipularán, aprovecharán.

3. Privación emocional. La expectativa de que sus deseos propios de tener un grado normal de soporte emocional (i.e., cuidado, empatía o protección) no se satisfacerán adecuadamente con los otros.

4. Defectuosidad/Vergüenza. El sentimiento que uno es defectuoso, malo, no querido, inferior o inválido en aspectos importantes; o de que uno sería no querido de forma significativa por los demás si se muestra tal como es.

5. Aislamiento social/Alienación. La sensación de que uno está aislado del resto del mundo, diferente de los demás y no participa o forma parte de un grupo o comunidad.

\section{2) Trastornos de autonomía y rendimiento}

6. Dependencia/Incompetencia. Creencia de que uno es incapaz de realizar sus responsabilidades diarias de forma competente, sin considerable ayuda de los demás.

7. Vulnerabilidad al peligro. Miedo exagerado a que una 'fortuita/azarosa' catástrofe podría ocurrir en cualquier momento y que no será capaz de prevenirla. Los miedos son médicos, emocionales, naturales/fobia.

8. Apego inmaduro independiente. Emocionalmente se encuentra excesivamente implicado y unido con una o más personas significativas -a menudo los padres-, a expensas de una completa individualización o un desarrollo social normal.

9. Fracaso. La creencia de que uno ha fracasado, inevitablemente fallará o que fundamentalmente resulta inadecuado en relación a los grupos de iguales, en áreas de rendimiento (e.g., escuela, carrera, deportes, etc.).

\section{3) Límites insuficientes}

10. Grandiosidad. La creencia de que uno es superior a los demás, que le da derecho a privilegios y derechos especiales; o no tener que limitarse por las reglas de reciprocidad que guían la interacción social habitual.
11. Insuficiente autocontrol. Dificultad persistente o negativa de emplear o usar el suficiente autocontrol y tolerancia a la frustración para conseguir sus propios objetivos, o contener/ reprimir de forma excesiva la expresión de sus emociones e impulsos.

\section{4) Focalización en los otros}

12. Subyugación. Excesivamente entregados/ abandonados al control de los demás porque uno se siente cohesionado: usualmente para evitar la cólera, represalias o el abandono. Las dos formas más importantes son la subyugación de necesidades y de emociones.

13. Autosacrificio. Excesivamente centrado de forma voluntaria en las necesidades de los demás en las situaciones diarias, a expensas de su propia gratificación.

14. Búsqueda de aprobación/Búsqueda de reconocimiento. Excesivo énfasis en encontrar aprobación, reconocimiento, o atención en los demás, o en llevarse bien, a expensas de desarrollar un sentido seguro y verdadero de uno mismo. Su autoestima depende principalmente de las reacciones de los demás más que de sus propias inclinaciones naturales.

\section{5) Hipervigilancia e inhibición}

15. Negatividad -eventos controlables-. Una penetrante focalización de toda la vida en los aspectos negativos de la cotidianeidad, mientras minimizan o niegan los aspectos positivos u optimistas, o una exagerada expectativa de que las cosas saldrán seriamente mal.

16. Inhibición emocional. Excesiva inhibición de la acción espontánea, sentimientos o comunicación, por lo general para crear un sentimiento de seguridad y pronóstico; o para evitar cometer errores, la desaprobación de los demás, catástrofe y caos, o la pérdida de control de los propios impulsos.

17. Metas inalcanzables. La creencia profunda que uno debe esforzarse por encontrar unos estándares internos de conducta y rendimientos muy elevados, normalmente para evitar las críticas.

18. Castigo. La creencia que las personas deben ser duramente castigadas al cometer errores, incluso él mismo. 


\section{Orígenes y clasificación de los esquemas}

Según este modelo, los ETI se originan en necesidades emocionales insatisfechas en la infancia. Éstas son necesidades básicas que todo niño tiene que tener cubiertas y debe aprender a compensarlas con sus padres, familia y el grupo de pares, con el fin de conseguir un óptimo desarrollo y funcionamiento adaptativo a lo largo de la vida. Estas cinco necesidades universales según Young y Klosko (2007) se enuncian como:

- Pertenencia. Integrada por:

- Seguridad

- Estabilidad

- Afecto, cariño

- Aceptación

- Autonomía, competencia y sentido de identidad.

- Libertad para expresar emociones y deseos válidos.

- Espontaneidad y juego.

- Límites realistas y autocontrol.

Finalmente, es importante señalar que Young y Klosko, (2007) han observado que existen cuatro tipos de experiencias vitales que promueven la aparición de los esquemas. La primera es la que denominan frustración tóxica de las necesidades que se produce cuando el niño recibe 'muy poco de algo bueno' y adquiere esquemas tales como la Privación emocional o Abandono/Inestabilidad, debido a ciertas deficiencias en su ambiente temprano. De esta manera, el ambiente del niño está perdiendo estabilidad, comprensión o amor. El segundo tipo de experiencia tóxica temprana hace referencia a la traumatización; en este sentido, el niño es dañado, criticado, controlado o victimizado. Estas experiencias llevan a que desarrolle esquemas tales como Abuso/ Desconfianza, o Vulnerabilidad al peligro. Con respecto al tercer tipo de experiencia tóxica, el niño recibe demasiado de algo bueno, es decir, los padres brindan al niño demasiado de algo que, en moderación, es saludable para él mismo, lo que a su vez contribuye a generar esquemas tales como Dependencia funcional o Grandiosidad. Por último, el cuarto tipo de experiencia tóxica consiste en la interiorización selectiva o identificación con otros significativos. Con respecto a este tipo de experiencia, el niño se identifica de manera selectiva e interioriza los pensamientos, las sensaciones y las experiencias de sus padres, en otras palabras, el niño lo que hace es interiorizar los esquemas de sus padres, lo que da lugar a que se origine, por ejemplo, el esquema de Vulnerabilidad.

\section{Los estilos y respuestas de afrontamiento}

Existen tres estilos desadaptativos de afrontamiento ante la frustración de las necesidades emocionales que mencionamos anteriormente. Se los puede definir como formas de hacer frente a las necesidades básicas, a los conflictos y a las situaciones estresantes, que refuerzan y mantienen a los ETI, y que empiezan de manera temprana para permitir una adaptación a los esquemas, para no experimentar las intensas y arrolladoras emociones que estos engendran (Young \& Klosko, 2007). Los tres estilos de afrontamiento desadaptativos hacen referencia a las tres respuestas básicas ante la amenaza: la lucha, la huída y el quedarse inmóvil; específicamente lucha es sobrecompensación, huida es evitación y quedarse inmóvil es rendición. Es importante tener en cuenta que si bien estos estilos de respuesta fueron posiblemente funcionales y útiles en la infancia, en la edad adulta podrían resultar disfuncionales porque no permiten adaptarse de una manera saludable y, por lo tanto, impiden la satisfacción de las necesidades básicas de todos los seres humanos (Young \& Klosko, 2007). Los pacientes suelen referirse a estas cosas como 'lo que nos hacen tropezar una y otra vez, con la misma piedra'. Los tres estilos de afrontamiento descritos por Young y Klosko (2007) son:

1. Sobre-compensación. Hace referencia a conductas, pensamientos y sentimientos con los que el sujeto intenta superar y hacer frente a un esquema. Muchas veces se pueden manifestar como conductas o estilos de funcionamiento totalmente contrarios a los que esperamos según el esquema en cuestión o el esquema predominante. Son intentos parciales de hacerle frente al mismo y a las emociones que generaría su activación, aunque como son excesivos o exagerados, habitualmente terminan en la activación del esquema. Entonces, si una persona fue sometida en la infancia, ahora es desafiante; si fueron controlados, desafían toda forma de influencia sobre ellos; tener un estilo de vida completamente 
autosuficiente y aparentando que nunca necesita nada, puede ser un intento de compensar sentimientos y creencias de incompetencia.

2. Evitación. Consiste en estrategias cognitivas, emocionales o conductuales con las cuales el sujeto intenta eludir los pensamientos o las situaciones que pudieran activar el esquema y la experimentación de la intensa emoción o tono emocional que le acompaña. Su instauración se realizaría por condicionamiento aversivo. Estos procesos pueden ser automáticos o intencionales, y se van desarrollando a lo largo de la vida del individuo. Explicarían por ejemplo la falta de expresión emocional ante eventos traumáticos, o el olvido de elementos autobiográficos significativos, como por ejemplo, malos tratos, abusos sexuales, etc.

3. Rendición. Consiste en aceptar plenamente y favorecer el cumplimiento o confirmación del esquema. Los pacientes buscan las relaciones que reiterarán las situaciones generadoras del esquema o reaccionan con excesiva intensidad emotiva ante disparadores del esquema. Por ejemplo, reiteran parejas abusivas o descalificadoras o generan reacciones negativas en otros y responden con exacerbado resentimiento 0 depresión ante esas reacciones.

Finalmente, se denomina respuestas de afrontamiento a las conductas concretas que se desarrollan de acuerdo a los esquemas y a los estilos de afrontamiento de cada paciente (Young \& Klosko, 2007). Para una mejor comprensión de los conceptos antes descriptos, en la Figura 1 se los esquematiza.

\section{Operaciones de los esquemas}

Young y Klosko (2007) reagruparon los estilos de afrontamiento desadaptativos en dos operaciones básicas de los esquemas:

1. La perpetuación. Incluye todo lo que hace el paciente (i.e., pensamientos, emociones o conductas) que sostiene y perpetúa al esquema.

2. La sanación. Incluye todo lo que haga el paciente que produzca la disminución de cualquiera de los componentes del esquema. Este sería el objetivo de la terapia, que implica disminuir la intensidad de los recuerdos conectados con el esquema, la carga emocional, la intensidad de las sensaciones corporales y las cogniciones desadaptativas. Esto también conlleva un cambio de la conducta, donde el paciente reemplaza los estilos de afrontamiento desadaptativos por patrones conductuales adaptativos.

\section{Los modos}

Las personas no tienen sus esquemas permanentemente activos, sino que éstos se activan en determinados momentos. A su vez, las personas disponen de diversos estilos de afrontamiento, pero no siempre los están utilizando. Frente a determinados disparadores la persona activa alguno(s) de sus esquemas. A su vez los esquemas activos despliegan alguno de los varios estilos de afrontamiento característicos de la persona, concretado en cada caso en una de las conductas posibles dentro de ese estilo.

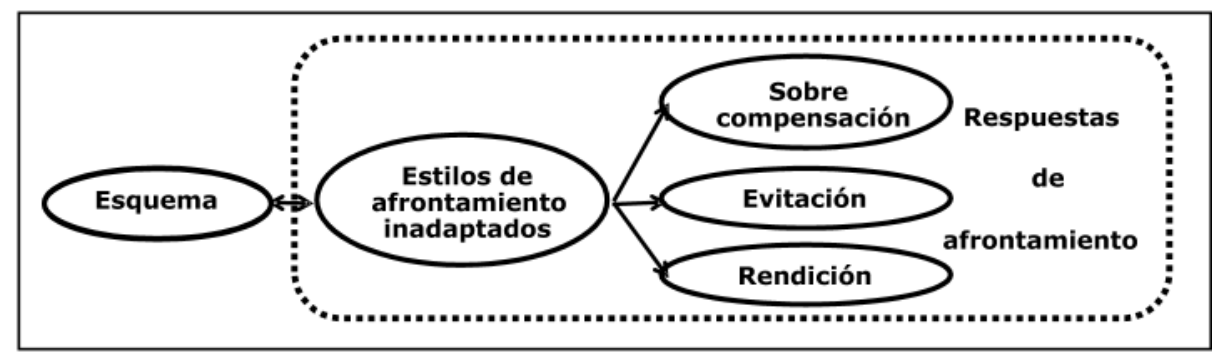

Figura 1. Estilos de afrontamiento inadaptados. Fuente: Lopez Pell et al., 2011. 
Sin embargo, podemos observar que ciertos esquemas y estilos de afrontamiento se disparan juntos. A estos esquemas y/o estilos de afrontamiento agrupados se les ha denominado modos (véase Figura 2). Los Modos hacen referencia a partes del sí mismo que contienen ETI y sus respectivos estilos de afrontamiento, los cuales no han sido integrados en una personalidad consistente. Los Modos consisten así en pensamientos, emociones y conductas relacionadas que forman parte de un patrón recurrente en la vida del sujeto. Los Modos son temporales y se activan ante determinados estresares (Young, Klosko \& Wheishar, 2003).

Las personas cambian sus modos en diversos momentos y ante diversas circunstancias. Asimismo, el concepto de modos en cierta forma se relaciona con un grado de disociación, siendo sus ejemplos más extremos el trastorno de personalidad múltiple y el trastorno de personalidad límite. Por su parte, las personas saludables, aunque exhiben diferentes modos, estos no son muy diferentes entre sí, generalmente son la combinación de varios, y en ellas el sentido de una única identidad permanece intacto.

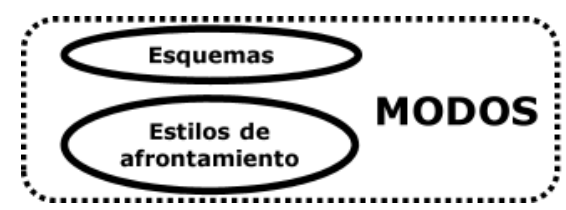

Figura 2. Modos.

Fuente: Lopez Pell et al., 2011.

En general podemos decir que los modos en cada persona pueden variar en sus características dentro de los siguientes parámetros (Young \& Klosko, 2007) que se presentan en la Tabla 1.

Tabla 1

Parámetros modales

Fuente: Lopez Pell et al., 2011

\begin{tabular}{ccc}
\hline Disociado & $\leftarrow \rightarrow$ & Integrado \\
\hline No consciente & $\leftarrow \rightarrow$ & Consciente \\
\hline Inadaptado & $\leftarrow \rightarrow$ & Adaptado \\
\hline Extremo & $\leftarrow \rightarrow$ & Leve \\
\hline Rigido & $\leftarrow \rightarrow$ & Flexible \\
\hline Puro & $\leftarrow \rightarrow$ & Mezclado \\
\hline
\end{tabular}

Los 10 modos descriptos por Young y Klosko (2007) se muestran en la Tabla 2.

Tabla 2

Modo

Fuente: Lopez Pell et al., 2011

\begin{tabular}{|c|c|c|}
\hline \multirow{7}{*}{ Modos de niño } & \multirow{4}{*}{ 1- Niño Vulnerable } & Abandonado \\
\hline & & Abusado \\
\hline & & Carente de afecto \\
\hline & & Rechazado \\
\hline & \multicolumn{2}{|l|}{ 2- Niño Enojado } \\
\hline & \multicolumn{2}{|c|}{ 3- Niño Impulsivo- Indisciplinado } \\
\hline & \multicolumn{2}{|c|}{ 4- Niño Feliz } \\
\hline \multirow{3}{*}{$\begin{array}{l}\text { Modos disfuncionales } \\
\text { de afrontamiento }\end{array}$} & \multicolumn{2}{|c|}{ 5- Sumiso-Claudicante } \\
\hline & \multicolumn{2}{|c|}{ 6- Distanciado Protector } \\
\hline & \multicolumn{2}{|c|}{ 7-Sobre-compensador } \\
\hline \multirow{2}{*}{$\begin{array}{l}\text { Modos parentales } \\
\text { disfuncionales }\end{array}$} & \multicolumn{2}{|l|}{ 8- Padre Punitivo } \\
\hline & \multicolumn{2}{|c|}{ 9- Padre Demandante } \\
\hline Modo funcional & \multicolumn{2}{|l|}{ 10- Adulto Saludable } \\
\hline
\end{tabular}

Según este modelo, podemos pensar que los Modos de niño son innatos y representan el campo emotivo de los seres humanos (Young \& Klosko, 2007). Describirían el estilo emocional del paciente, y se le presupone influencia de variables temperamentales. Si bien los acontecimientos o circunstancias de la infancia pueden reducir, anular o incrementar los modos de niño, todas las personas nacen con la capacidad de manifestarlos.

- El modo Niño Vulnerable es considerado nuclear para el abordaje de los modos y el más importante para sanar. Este modo se puede ver como la conducta de un niño asustado, triste o incapaz, necesitado del cuidado, que no tiene, de los adultos. El esquema y la causa de este modo puede ser alguno de los siguientes: 'Abandonado' (i.e., haber sido dejado solo), 'abusado' (i.e., haber sido muy castigado o maltratado), 'carente de afecto' (i.e., no haber recibido cariño) o 'defectuoso' (i.e., haber sido muy criticado o descalificado). También puede relacionarse con otros esquemas como: 'vulnerable' (i.e., en riesgo de sufrir un daño o de enfermarse), 'dependiente' (i.e., incapaz de desenvolverse sin ayuda) o 'fracasado' (i.e., incapaz de éxito, nunca exitoso). Es decir, el modo Niño Vulnerable puede contener esquemas del dominio I (i.e., desconexión temprana y rechazo), generalmente originados en entornos familiares fríos, lejanos, explosivos, abusivos o impredecibles, o en esquemas del grupo II (i.e., trastornos de autonomía y rendimiento) generalmente originados en entornos familiares sobre-protectores o que desalientan el desempeño independiente o la auto-confianza. 
- El modo Niño Enojado surge como respuesta a la necesidad de un tratamiento justo no obtenido o a situaciones que activan esquemas de abandono, abuso, sometimiento o falta de afecto. En este modo el paciente se enfurece, grita o reacciona violentamente (e.g., el niño que tiene una 'rabieta' al no obtener algo).

- El modo Niño Impulsivo o Indisciplinado exhibe poca tolerancia a la frustración o poca capacidad de postergación, realizando cualquier deseo o 'necesidad' sin previsión de consecuencias, sin límites ni consideración hacia los demás. Este modo suele aparecer junto con esquemas del dominio III, como el de 'Derechos/ Grandiosidad' o el de 'Insuficiente Auto-control o Autodisciplina'.

- El Niño Feliz es el modo propio de una saludable ausencia de activación de esquemas inadaptados.

Los Modos de Estilos de Afrontamiento Desadaptativos se entienden como los estilos de afrontamiento que se van aprendiendo para hacer frente a los Modos de niño, y hacen referencia a cómo las personas resuelven las situaciones conflictivas y manejan las emociones asociadas (Young \& Klosko, 2007). Asimismo se corresponden con los tres estilos inadaptados de afrontamientos descriptos con anterioridad:

- El modo Sumiso corresponde al estilo 'rendición'. La persona se muestra pasiva, hace todo lo que otras personas desean que haga y puede ser obediente hasta el grado de permitir el abuso o la descalificación, para conservar la relación o evitar reacciones negativas o venganzas.

- El modo Distanciado corresponde al estilo 'evitación'. La persona adopta conductas de retraimiento, evitación de situaciones, desconexión de emociones, aislamiento, etc.

- El modo Sobre-compensador corresponde al estilo de 'sobre-compensación'. En este modo las personas obran como si fuera verdad todo lo opuesto a su esquema inadaptado. Si se creen defectuosos, actúan como perfectos o superiores a otros; si se creen culpables, acusan a los otros.

Los 'Modos disfuncionales parentales' surgen cuando el paciente incorpora las conductas disfuncionales de sus padres. Sería la voz internalizada de los padres, que correspondería a enseñanzas o mandatos de los padres que en la vida adulta no permiten una adecuada adaptación. Las dos formas más comunes son:
- El padre castigador, que critica y sanciona los errores o reprime la expresión de las necesidades del niño.

- El padre demandante, que no castiga sino que pretende la perfección, los máximos niveles de realización, y se desilusiona o se muestra defraudado cuando no se cumplen, generando culpa o vergüenza en el niño.

Estos modos parentales disfuncionales suelen encontrarse en casos de severa depresión y en trastornos obsesivo-compulsivos.

Por último, dentro del 'Modo funcional':

- El modo Adulto saludable correspondería a todas las cosas buenas del autoconcepto del paciente, que permite generar una sensación de autoeficacia en las propias habilidades, autoestima para poder avanzar y compasión para poder aceptar las experiencias vitales negativas. En las personas saludables, este modo se activa con mayor frecuencia, está casi siempre presente y tiene fuerza suficiente para moderar a los otros modos cuando aparecen.

La finalidad de la terapia es desarrollar y aumentar la presencia y fuerza del modo adulto saludable enseñándole al paciente a moderar, suavizar o 'sanar' a los otros modos (Young \& Klosko, 2007).

\section{El temperamento}

Como ya se hizo referencia, los modos de niño están influenciados por variables temperamentales. En este sentido, cada niño desde su nacimiento tiene un temperamento distinto, una forma innata de reaccionar emotivamente, de origen biológico y muy estable a través de toda la vida o muy difícil de modificar. Este temperamento interacciona con los acontecimientos de la vida, tanto en la determinación de la respuesta ante determinadas situaciones, favoreciendo ciertas emociones y conductas, como en la generación de las mismas situaciones. Asimismo, el temperamento de cada persona puede definirse de acuerdo a siete parámetros en puntos intermedios entre los dos extremos de cada uno.

Tabla 3

Parámetros temperamentales

Fuente: Lopez Pell et al., 2011

\begin{tabular}{|c|c|c|}
\hline Lábil & $\leftarrow \rightarrow$ & No reactivo \\
\hline Distímico & $\leftarrow \rightarrow$ & Optimista \\
\hline Ansioso & $\leftarrow \rightarrow$ & Calmo \\
\hline Obsesivo & $\leftarrow \rightarrow$ & Disperso \\
\hline Pasivo & $\leftarrow \rightarrow$ & Agresivo \\
\hline Irritable & $\leftarrow \rightarrow$ & Contento \\
\hline Tímido & $\leftarrow \rightarrow$ & Sociable \\
\hline
\end{tabular}


A su vez, el temperamento influye en el estilo de afrontamiento que cada persona desarrolla ante sus esquemas y es un componente importante en la determinación de la forma en que una persona responderá a su entorno. Un estilo de temperamento no es ni bueno ni malo cada estilo tiene tanto ventajas como desventajas. El temperamento es muy resistente al cambio. Sin embargo, el paciente puede aprender a moderar sus respuestas emotivas y a modificar o hasta suprimir algunas conductas disfuncionales favorecidas por su temperamento (Young \& Klosko, 2007).

Finalmente y a modo de síntesis en la figura 3 ilustramos los conceptos fundamentales de la Teoría de Esquemas desarrollados a lo largo de este trabajo.

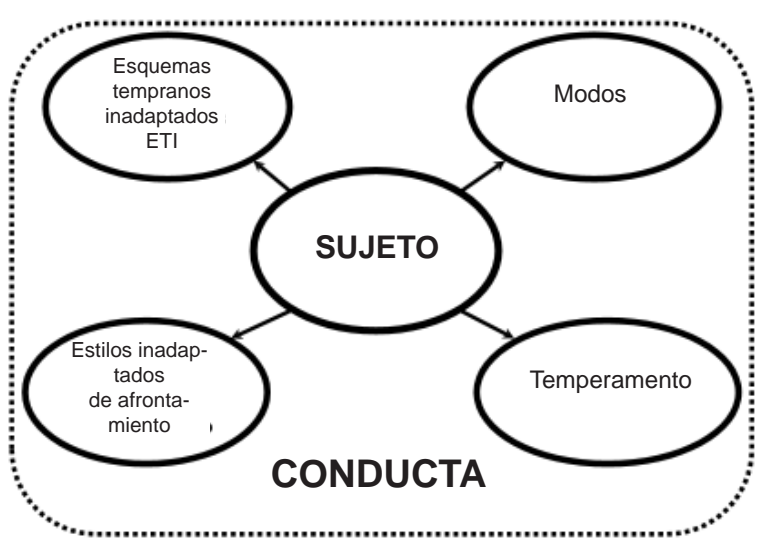

Figura 3. Conceptos fundamentales de la Teoría de Esquemas. Fuente: Lopez Pell et al., 2011.

\section{ESTRATEGIAS DIAGNÓSTICAS}

Dentro del tratamiento de los trastornos de personalidad, la primera etapa es la de evaluación, cuyos objetivos según Young (1996) son:

1. Identificar los esquemas centrales de la vida del paciente, hacerlos relevantes en la conciencia, y delimitar su importancia en el funcionamiento psicológico.

2. Unir los esquemas con los problemas actuales y de la historia de vida o experiencial.

3. Hacer entrar al paciente en contacto con las emociones circundantes a estos esquemas.

4. Identificar los estilos de afrontamiento disfuncionales que refuerzan los esquemas.
La evaluación es un proceso de concientización, que implica una construcción conjunta donde terapeuta y paciente identifican cuales son los temas que definen la experiencia -que es dolorosa y que causa sufrimiento emocional-, se acceden a los recuerdos que van configurando las maneras de dar significado al sí mismo -la continuidad y persistencia del sufrimiento-, y se explicitan los estilos de afrontamiento que se utilizan para funcionar en la vida -consecuencias y refuerzo del sufrimiento-. Para lograr esto, muchos son los recursos con los que se cuenta. Entre ellos, los más frecuentes son:

\section{Los cuestionarios}

Entre ellos se destacan:

- Cuestionario de Esquemas de Young (Young Schema Questionnaire, 2001): Es el instrumento más conocido y consiste en un inventario auto-administrado que evalúa qué Esquemas Tempranos Inadaptados tiene probablemente un paciente. Este cuestionario tiene una versión larga -compuesta por 205 ítems- y una versión corta -de 75 ítems-y sus diferentes versiones han sido adaptadas a numerosas lenguas, tales como holandés (Rijkeboer \& van den Bergh, 2004), castellano (Cid, Tejero \& Torrubia, 1997; Cid \& Torrubia, 2003), coreana (Baranoff, Oei, Seong \& Seok-Man, 2006), Portugués (Gouveia, Chaves, Oliveira, Dias, Gouveia \& Andrade, 2003), etc.

- Inventario de Estilos Parentales de Young (Young Parenting Inventory, 1994b): Inventario auto-administrado de 72 ítems que identifica el origen probable de cada esquema para un paciente en particular.

- Inventario de Evitación de Young y Ryght (Young-Ryght Avoidance Inventory, 1994): Inventario auto-administrado de 40 ítems que mide el grado en que el paciente utiliza diversas formas de evitación del o los esquemas.

- El Inventario de Compensación de Young (Young Compensation Inventory, 1995): Inventario auto-administrado de 48 ítems que mide las formas más comunes que un paciente utiliza para sobrecompensar sus esquemas.

- El Inventario de modos de esquema (The Schema Mode Inventory, Young, et al, 2007). Inventario auto-administrado de 124 ítems que mide los modos de esquemas.

- Historia Multimodal de vida (Lazarus, 2000). Cuestionario auto-administrado que tiene por objetivo la construcción detallada de la historia clínica del sujeto. Se le solicita a la persona que 
describa conflictos familiares y características vinculares, entre otros hechos de su infancia y adolescencia.

\section{Los ejercicios de imaginación}

Los ejercicios en que el paciente revive emotivamente situaciones perturbadoras han demostrado gran utilidad. El generar nuevamente las emociones propias de las situaciones originales, es el recurso más sólido que disponemos para acceder a los pensamientos que las generan (Young \& Klosko, 2007). Aunque en el ejercicio la situación no esté sucediendo realmente, las emociones son reales, y si las emociones son reales es porque están presentes las cogniciones que las generan. Dicho en pocas palabras: el ejercicio de imaginación dispara el esquema en el consultorio. Imaginar la situación permite tener la emoción y la cognición correspondientes en la misma sesión y disponibles en ese momento para la observación del terapeuta y el paciente.

En la práctica, esto se puede instrumentar de muchas formas. Por ejemplo, una forma de frecuente utilidad consiste en hacer que el paciente primero reviva en imaginación la situación que le generó la respuesta disfuncional o la emoción disfuncional actual. Luego, se le pide recordar situaciones anteriores, hasta llegar a una experiencia de su infancia en que sintió lo mismo. Esto suele conectar al paciente con la situación traumática que dio origen al esquema temprano inadaptado. El reconocimiento de esa situación, la comparación y diferenciación de la actual, la resignificación de la situación primitiva y otros ejercicios de fuerte contenido emotivo, característicos del psicodrama, suelen superar en eficacia a los simplemente cognitivos tradicionales.

El obstáculo más frecuente a este recurso parece ser el estilo evitativo, que se manifiesta cuando el paciente presenta dificultades, se resiste 0 'no puede' hacer estos ejercicios (Young \& Klosko, 2007). En primer lugar, esta dificultad es útil para conocer su estilo y también puede superarse, lentamente, con la discusión del problema y/o con ejercicios menos comprometidos al comienzo.

\section{Las preguntas y los reportes}

Las preguntas directas al paciente y los informes del paciente solicitados y presentados de diversas maneras, son también un recurso válido para conocer su temperamento, sus esquemas, sus modos, estilos de afrontamiento, etc.

\section{La conducta en la terapia}

La observación de la conducta del paciente en la terapia, en su relación con el terapeuta, en las tareas asignadas, etc. es otra forma natural y válida de conocer su temperamento, sus esquemas, sus modos, estilos de afrontamiento, etc. Su relación con el terapeuta muestra sus modos, de la misma manera que puede mostrar los modos del terapeuta.

\section{Relato de su historia}

La historia del paciente, los hechos que le sucedieron, la forma en que reaccionó, cómo reaccionaron los otros, incluyendo los principales acontecimientos de su infancia, y especialmente los traumáticos, son otra forma posible de acceder a sus esquemas, modos, etc. Por eso, esta es una información importante en esta etapa.

\section{Otros recursos}

Existen muchos recursos posibles, ya que el modelo no descarta ninguno. Entre otros posibles, se encuentra el relato -o representación- de los sueños, especialmente los reiterados y/o con mucho contenido emotivo. El contenido de la Tabla 6 servirá para poder integra estos recursos a la conceptualización del caso.

\section{SÍNTESIS DEL TRATAMIENTO PROPUESTO POR YOUNG, KLOSKO Y WHEISHAR (2003)}

Luego de haber llevado a cabo, junto con el paciente, una adecuada evaluación de los aspectos centrales antes planteados, tendrá lugar una segunda fase denominada proceso de cambio (Young \& Klosko, 2007). Esta etapa tiene como objetivo principal de tratamiento un cambio en los esquemas y estilos de afrontamiento identificados, lo que significaría en mayor o menor grado: (a) un cambio en la forma de verse a sí mismo; (b) una consecución de unos patrones de vida más flexibles -modificación de estilos de afrontamiento-; (c) una adaptación más óptima a su medio y (d) una disminución del malestar psicológico. Esto implica, por lo general, utilizar diferentes estrategias según los diferentes componentes de los esquemas. Para ello, el terapeuta despliega una amplia gama de técnicas y recursos que debe intentar mezclar de una forma flexible y creativa, de acuerdo a cada 
caso y paciente en particular. Estas técnicas y recursos, hacen referencia a estrategias cognitivas, experienciales, conductuales, e interpersonales que se describen a continuación:

\section{Las Estrategias Cognitivas}

Según lo expuesto por Young y Klosko (2007) el objetivo de la utilización de estrategias cognitivas es desarrollar una voz saludable para crear una distancia. Es decir, se trata de poner a prueba lo inadecuado del esquema desde la distancia cognitiva. Para ello es necesario conocer qué experiencias están asociadas al esquema aportando evidencias que mantienen al mismo. Las técnicas que se utilizan mayoritariamente provienen de la terapia cognitiva, siendo las más utilizadas:

- Revisar las evidencias o argumentos a favor y en contra del esquema. Hacer las listas de ellas y discutirlas.

- Discutir y evaluar nuevas interpretaciones posibles de las evidencias presentadas a favor del esquema, de acuerdo a puntos de vista más maduros y amplios.

- Evaluar beneficios vs. desventajas de los estilos de afrontamiento del paciente.

- Role-play de diálogos entre el 'lado del esquema' y el 'lado sano', cambiando roles con el terapeuta.

- Escribir y disponer de tarjetas de afrontamiento (i.e., flashcards) donde se pueden leer los argumentos y pensamientos apropiados para enfrentar el esquema cuando se activa.

- Utilizar el Registro Diario de Esquemas (Young, 1993) donde el paciente registra los siguientes datos: disparador, emoción, pensamiento, conducta real, esquemas, punto de vista saludable, consideraciones realistas, sobre-reacciones, conducta saludable.

\section{Las Estrategias Experienciales}

Pueden también denominarse 'técnicas emotivas' por la importancia del compromiso emotivo que incluyen (Cid, 2009). Tienen como objetivo activar las emociones conectadas con los esquemas y habilitar al paciente mediante la descarga del dolor temprano, para así satisfacer de manera parcial las necesidades emocionales no cubiertas. Esto permite al paciente no sólo creer que los esquemas son falsos, sino también sentir que emocional- mente lo son. Young et al (2003) propone las siguientes técnicas:

Técnicas de imaginación -o dramatizaciones-:

Las actuaciones, usando los recursos del psicodrama (Moreno, 1975) (Blatner, 1996) (Blatner \& Blatner, 1988) permiten la implicación emotiva necesaria para actuar sobre los esquemas.

- Diálogos. Pueden ser con las personas que originaron sus esquemas disfuncionales. Además, puede ser útil para expresar sentimientos, por ejemplo, la ira puede servir para confirmar sus derechos, pero en un segundo paso se recomienda seguir con este recurso para lograr la integración, la comprensión de la situación, la liberación de la culpa y mejorar el nivel de auto estima del paciente.

- Re-actuación parental. En esta estrategia, el terapeuta solicita entrar en la escena imaginada y así brinda la contención o reparación desde el lugar del padre o simplemente desde el 'adulto saludable'. Luego lo hará el mismo cliente, intercambiando roles, inicialmente con la ayuda del terapeuta. Estos diálogos del paciente 'niño' con el paciente 'adulto', o del paciente con 'el anciano sabio' han sido largamente utilizados por el psicodrama y por otras escuelas como la gestalt, durante más de 50 años con excelentes resultados.

- Recuerdos traumáticos. Este ejercicio brinda en primer lugar la liberación de los sentimientos hasta ahora bloqueados para lograr su lenta aceptación e integración, a veces en sucesivos pasos con reiteradas experiencias. En segundo lugar brinda la posibilidad de integrar la acción reparadora del 'adulto saludable' como se explicó en el ejercicio anterior.

- Modificación de patrones. Imaginarse actuando en formas alternativas, diferentes a sus pautas disfuncionales es una preparación, un ensayo de menor riesgo, para poder hacerlo luego con mayor nivel de riesgo en la vida real. Primero la imaginación, luego la dramatización y finalmente la vida real, son grados crecientes de 'riesgo' para lograr vencer progresivamente el miedo a las nuevas conductas.

\section{Otras tareas y técnicas}

- Escribir una carta. Una técnica experiencial frecuentemente útil es escribir una carta -o varias- a uno de los padres o a la persona que haya generado la situación traumática o el esquema temprano inadaptado. La carta podría incluir 
cómo se sintió el cliente ante esas situaciones y lo que no pudo decir. Es un ejercicio menos difícil que la fantasía de estar enfrente a la persona y suele brindar similares beneficios. Esto no incluye, y en general no se recomienda, enviar la carta realmente a la persona, a menos que se hayan evaluado bien las posibles consecuencias y asegurado de que serán positivas -lo cual es poco probable en la mayoría de los casos-, y porque el objetivo se logra sin necesidad de esto.

Más opciones: Medicación, trabajo corporal, etc.

Cuando se encuentran dificultades, se puede recurrir a recursos adicionales, como la medicación para disminuir -pero nunca suprimir- la ansiedad ante las nuevas tareas. También hay muchos recursos como las técnicas de relajación y otros propios de las técnicas corporales, desarrollados por la terapia gestalt (Kepner, 1987), por el análisis de la relación (Lapierre \& Aucouturier, 1990), y por otras escuelas, que pueden ser útiles con ciertos pacientes para ayudar al proceso de cambio requerido en esta etapa.

\section{Las estrategias conductuales}

Luego de realizados los pasos anteriores, el terapeuta se avoca a modificar los patrones de conducta o estilos de afrontamiento inadaptados que perturban al cliente. En esta etapa se trabajará para modificar las conductas disfuncionales pertenecientes a los estilos de rendición, evitación o sobre-compensación del paciente, para que puedan ser reemplazados por estilos de afrontamiento más saludables.

Cuando el terapeuta considera que su cliente ha aprendido a reconocer sus esquemas inadaptados cuando son disparados, a entender sus orígenes y a entablar con ellos las discusiones para vencerlos, racional y emotivamente, puede entonces encarar esta etapa final de modificación de sus respuestas inadaptadas, la cual se lleva a cabo de la siguiente manera:

- Hacer la lista de conductas. Se elabora de común acuerdo una lista de todas las conductas que merecen ser objeto de cambio. Para ello se trata de analizar distintas áreas de la vida, como el trabajo, las actividades sociales, las relaciones íntimas, etc. ya que cada una puede desarrollar distintos esquemas y/o distintos estilos de afrontamiento. Esto requiere una descripción detallada de cada situación y conducta, para lo cual a veces puede no ser suficiente la que haga espontáneamente el paciente, que puede estar distorsionando u omitiendo cosas. La observación de sus conductas con el terapeuta, lo que surja de ejercicios de imaginación -o dramatizaciones- de situaciones disparadoras y lo que otros allegados al paciente informen, son recursos posibles para asegurar una correcta y completa descripción de las conductas disfuncionales a encarar.

- Elegir la conducta a modificar. Ordenadamente se decidirá cuál será la primera conducta a abordar en primer lugar. Como guía general se recomienda elegir primero una conducta claramente determinada, en vez de plantear 'cambios generales de vida'. También es aconsejable comenzar con la que mayores problemas cause al cliente, la que más interfiere con sus metas o deseos, la que mayores deseos o motivos tenga para cambiar. Esto siempre que no resulte demasiado difícil o extenuante para este cliente el trabajo de modificarla.

- Generar la motivación necesaria. Sin la motivación necesaria el paciente no realizará el esfuerzo. Para lograrla paciente y terapeuta pueden trabajar en realizar una lista de ventajas y desventajas de seguir con la misma conducta y de cambiar la conducta.

- Implementar los recursos de cambio más eficaces. Para este proceso existen todos los recursos conocidos y habituales de las terapias cognitivas conductuales. Algunos de los más eficaces suelen ser: las tarjetas de afrontamiento (i.e., flash cards), el ensayo de la nueva conducta en ejercicios de imaginación -o en dramatizaciones-, la asignación permanente al final de cada sesión de tareas a realizar y la revisión de la realización de esas tareas al comienzo de la siguiente sesión.

- Trabajar con los obstáculos. Cuando el paciente no hace las tareas, lo fundamental es investigar los motivos para vencerlos. Puede haber causas externas, como acontecimientos imprevistos, una planificación poco clara o precisa, tareas excesivamente difíciles, etc. Pero también puede haber causas internas, como pensamientos, supuestos, esquemas, etc. del paciente referentes a la tarea, a la terapia o a sí mismo que fueron subestimadas o no tenidas en cuenta.

Si la causa es interna se debe discutir con el paciente, como todo pensamiento o esquema disfuncional, hasta lograr superarla.

Si la causa es externa, corresponde modificar la tarea, hacerla menos difícil para ir paso a paso, 
o bien reemplazarla por otra. En algunos casos, si la modificación de la conducta elegida resulta demasiado difícil en esta etapa, o si no se puede lograr suficiente motivación para el esfuerzo de cambiarla, puede elegirse comenzar por otra conducta, dejando la anterior para más adelante.

Finalmente, cabe mencionar que para modificar las conductas disfuncionales, se utilizarán estrategias que provienen de las técnicas de la terapia de conducta tales como: entrenamiento en relajación, entrenamiento en asertividad, estrategias de autocontrol, exposición graduada a las situaciones temidas, etc.

\section{Las estrategias interpersonales}

La relación terapéutica es un elemento de gran importancia en este tipo de trastornos. Young et al (2003) consideran que en la relación terapeuta-paciente de la Terapia de los Esquemas hay dos elementos característicos:

- La confrontación empática. Debatir los conceptos y puntos de vista del paciente desde un punto de vista empático, entendiendo sus motivos, sintiendo lo que él siente, 'poniéndonos en su lugar'. Es decir, la confrontación empática implica expresar la comprensión de las razones por las que mantienen el esquema los pacientes, mientras que simultáneamente se les confronta la necesidad de cambio.

- La re-actuación parental limitada. Actuar en la forma que hubiera necesitado ese paciente que actúen sus padres y cuya falta consideramos que es la causa de sus esquemas disfuncionales. En otras palabras, brindarle al paciente dentro de la relación terapéutica las necesidades emotivas insatisfechas de la infancia causantes de sus esquemas tempranos inadaptados. En este sentido, puede decirse que el terapeuta se convierte en una figura parental transitoria, pero distinta a la original con respecto a las características causantes del trauma. El terapeuta tratará de actuar de manera claramente diferente a la causante del esquema., tratando así de desarrollar antídotos ante la activación de los esquemas. Finalmente cabe aclarar que hay que estar preparado para la hostilidad del paciente, el criticismo, los enfados, la desgana, la inhibición, etc.

En síntesis, la fase de cambio es un proceso centrado en la relación terapéutica, en el cual se intenta crear una cierta distancia, primero cognitiva y después emocional, que permita realizar una re-valoración del sí mismo o autoconcepto, y a su vez, dé lugar al aprendizaje y uso de estrategias que posibiliten un manejo emocional y conductual de las necesidades de la persona que le permitirá una mejor adaptación interpersonal, familiar y social.

\section{GUÍAS ESQUEMATIZADAS PARA PROFE- SIONALES PARA LOS TRASTORNOS DE PERSONALIDAD DESDE LA TERAPIA DE ESQUEMAS}

Los tratamientos psicológicos para los Trastornos de la personalidad todavía no alcanzan un grado de protocololarización tan específico como para describir las intervenciones para cada sesión. Esto podría deberse, entre otras cosas, a la heterogeneidad de los casos que dificultaría la posibilidad de diseñar un protocolo. Los tratamientos entonces se basan en conceptualizaciones de caso sustentadas teóricamente que después determinan los objetivos y las intervenciones a realizar. La dificultad para conceptualizar desde determinado modelo puede que sea una razón por la que a los psicoterapeutas les costaría realizar el tratamiento más adecuado. Para afrontar este problema hemos diseñado unas 'Guías esquematizadas para profesionales' para mejorar la práctica de la psicoterapia para los trastornos y alteraciones de la personalidad. Estas guías son de una carilla para tenerlas a la vista durante las sesiones a fin conceptualizar los casos y guiar más fácilmente las intervenciones desde este modelo.

La Terapia de Esquemas define las intervenciones terapéuticas en los Trastornos de la Personalidad (TP) en base a una conceptualización del caso idiosincrásica para cada paciente, que se basa en la identificación de los esquemas precoces desadaptativos y los estilos de afrontamiento desadaptativos. El objetivo de las intervenciones en la TE es la curación de los esquemas, esto implica por un lado, disminuir la intensidad de los recuerdos conectados con el esquema, la carga emocional, la intensidad de las sensaciones corporales, y las cogniciones que llevan a sesgos cognitivos; y por otro lado, un cambio de la conducta, donde el paciente reemplaza aquellos estilos de afrontamiento disfuncionales por patrones conductuales más adaptativos.

Cabe aclarar que este trabajo constituye un intento de facilitar la práctica de la TE desarrol- 
lada por Young et al (2003). La forma en que se han sistematizado sus principales conceptos, aportes, métodos y técnicas de intervención es una aporte de los autores de este trabajo. En sí se propone una estructura organizativa para facilitar la aplicación clínica del modelo de TE desarrollado por Young y sus colaboradores.

La estructura del de este apartado se basa, en primer lugar, en la identificación de las estrategias de intervención paso a paso de la TE en los TP en el modelo original o donde los esquemas se trabajarían según un modelo de rasgos de personalidad (Young, 1990; 1994a; 2003) y que es aplicable a los TP, que en el DSM-IV TR (APA, 2002) están organizados en el Cluster A y C, y al TP Histriónico y Antisocial (i.e., trabajar sobre ciertos patrones predominantes en cada personalidad). En segundo lugar, se intentará definir los aspectos clave de la evaluación y la intervención de la TE para cada trastorno. Antes de continuar, es importante señalar que este aspecto se opone a la propuesta de la TE ya que lo interesante del modelo de esquemas es que realiza una aproximación basada en los elementos internos y subjetivos de la personalidad y rehúye del diagnóstico de TP. Es sabido que el diagnóstico de TP está fundamentalmente basado en el repertorio conductual que muestra la persona a lo largo de la vida, que presenta problemas de fiabilidad y que difícilmente guía a la intervención psicológica. Por lo tanto, este punto debe considerarse de manera pragmática, como una herramienta tentativa en formato de guía esquematizada para profesionales. La excepción será con respecto al TP Límite (Arntz \& van Genderen, 2009) y Narcisista (Behary, 2008) donde se realizará la guía en base a los modos o estados de ánimo de Esquemas y donde la propuesta de intervención será más consistente al haber estudios empíricos (Giesen-Bloo, van Dyck, Spinhoven, van Tilburg, Dirksen, van Asselt, Kremers, Nadort \& Arntz, 2006; Nadort, Arntz, Smit, Giesen-Bloo, Eikelenboom, Spinhoven, van Asselt, Wensing \& van Dyck, 2009; Nadort, van Dyck, Smit, Giesen-Bloo, Eikelenboom, Wensing, Spinhoven, Dirksen, Bleecke, van Milligenese, van Vreeswijk \& Arntz, 2009) y de casos clínicos que avalan la intervención en los modos esquemas.

\section{Estructura y las estrategias de intervención generales de la TE en los TP}

El modus operandi de la TE en la evaluación e identificación de los esquemas (ver Tablas 1 , 2 y 3) es un proceso de concientización que implica una construcción conjunta donde terapeuta y paciente identifican cuáles son los temas que definen la experiencia (i.e., que es dolorosa y que causa sufrimiento emocional), se acceden a los recuerdos que van configurando las maneras de dar significado del sí mismo (i.e., la continuidad y persistencia del sufrimiento) y se explicitan los estilos de afrontamiento que se utilizan para funcionar en la vida (i.e., consecuencias y refuerzo del sufrimiento). La evaluación termina con la conceptualización del caso que se comparte con el paciente y se identifica la idoneidad de una intervención basada en esquemas y del tipo de intervención: modelo original de rasgos o modos de esquemas. En el caso de los TP del Cluster Ay $C$ del DSM-IV TR (2002), utilizaremos los modos de esquemas cuando hay un estilo rígido de afrontamiento evitativo o compensatorio, criticismo y autolesiones, confusión como consecuencia de los conflictos internos y fluctuación muy rápida de estados de ánimo y estilos de afrontamiento (Young, 1996). El trabajo de identificación de los modos de Esquemas es más emocional y la intervención tiene que ver con el proceso de manejo de las emociones y de atribución de significados idiosincrásicos desadaptativos en el aquí y ahora (Cid, 2008).

La fase de cambio (ver Tabla 4) es un proceso donde, centrándose en la relación terapéutica, se intenta crear cierta distancia, primero cognitiva y después emocional que permita realizar una revaloración del sí mismo o autoconcepto que permita el aprendizaje y el uso de estrategias para lograr un manejo emocional y conductual de las necesidades de la persona que permitirán una mejor adaptación interpersonal, familiar y social. En el caso del modelo de rasgos, el orden de estrategias de intervención va a ser primero estrategias de cambio cognitivas, después experienciales y conductuales. Las estrategias de relación terapéutica estarán presentes desde el inicio y se utilizarán en la activación de los esquemas, para poder trabajar en la sesión el impacto de éstos en el paciente y el terapeuta. Conviene resaltar el buen uso de la confrontación empática y la re-actuación parental limitada, como se ha explicado en los apartados introductorios. 
Tabla 4

Taxonomía de Esquemas tempranos inadaptados

Taxonomía de Esquemas tempranos inadaptados y sus dominios

1. Separación y Rechazo

La expectativa de que las propias necesidades de seguridad, defensa, estabilidad, cuidado, empatía, compartir sentimientos, aceptación y respeto no se van a satisfacer de forma previsible.

La percepción de inestabilidad o de poca seguridad de que se dispone de

Abandono/lnestabilidad soporte y relación con los demás. Incluye la expectativa acerca de que los demás irremediablemente los abandonarán.

Desconfianza/Abuso La expectativa de que lo herirán, abusarán, humillarán, burlarán, mentirán, manipularán, aprovecharán.

La expectativa de que el propio deseo de tener un grado normal de soporte

Privación emocional emocional no se encontrará o no será satisfecho de modo adecuado por los demás.

Imperfección/Nergüenza

El sentimiento que se es defectuoso, malo, no querido, inferior o inválido en aspectos importantes; o que no será querido si se muestra tal como es.

Aislamiento social

El sentimiento de que uno está aislado del resto del mundo, diferente de los demás y no participa o forma parte de un grupo o comunidad.

2. Autonomía y Desempeño deteriorados

Expectativas acerca de uno mismo y el ambiente que interfiere con la percepción de su habilidad para separar, sobrevivir, funcionar independientemente o desempeñarse con éxito.

Dependencia/Incompetencia

Vulnerabilidad al peligro y a la enfermedad

Creencia de que uno es incapaz de realizar sus responsabilidades diarias de forma competente, sin considerable ayuda de los demás.

Miedo exagerado a que una 'fortuita/azarosa' catástrofe podría ocurrir en cualquier momento y que no será capaz de prevenirla.

Apego/Yo inmaduro (a con una o más personas significativas (a menudo los padres), a expensas de una completa individualización o un desarrollo social normal.

La creencia que uno ha fracasado, inevitablemente fallará o que resulta

Fracaso inadecuado en relación a los grupos de iguales o en áreas de rendimiento (escuela, carrera, deportes, etc.) A menudo implica creencias de que uno es estúpido, inepto, sin talento, ignorante, de bajo estatus, con menos éxito que los demás, etc

Deficiencia en los límites internos, en las responsabilidades con los demás o en

3. Límites insuficientes los objetivos a largo plazo. Conduce a tener dificultades en respetar los derechos de los demás, cooperar con ellos, cumplir obligaciones o delimitar y encontrar objetivos personales realistas.

La creencia de que uno es superior a los demás, que le da derecho a privilegios

Grandiosidad y derechos especiales; o no tener que limitarse por las reglas de reciprocidad que guian la interacción social habitual.

Insuficiente autocontrol

Dificultad persistente o negativa de emplear/o usar el suficiente autocontrol y tolerancia a la frustración para conseguir sus propios objetivos o contener/reprimir de forma excesiva la expresión de emociones e impulsos.

Una focalización en los deseos, sentimientos y respuestas de los demás a expensas de sus propias necesidades para ganar amor y aprobación, mantener su sentido de unión o relación o evitar represalias. Por lo general implica la supresión y la poca conciencia de considerar su propia cólera e inclinaciones naturales.

4. Orientación hacia los Otros Excesivamente entregados o abandonados al control de los demás porque se sienten cohesionados, usualmente para evitar la cólera, represalias o abandono

Subyugación Excesivamente centrado de forma voluntaria en las necesidades de los demás en las situaciones diarias, a expensas de su propia gratificación.

Búsqueda de

aprobación/Búsqueda de reconocimiento

Excesivo énfasis en encontrar aprobación, reconocimiento, o atención, o en llevarse bien, a expensas de desarrollar un sentido seguro y verdadero de uno mismo. Su autoestima depende principalmente de las reacciones de los demás.

Excesivo énfasis en controlar sentimientos espontáneos, impulsos y en la elección para evitar cometer errores. Presenta rigidez en las reglas internalizadas y expectativas acerca del rendimiento y conductas éticas, a menudo a expensas de felicidad, autoexpresión, relajación, relaciones cerradas o salud.

Una focalización de toda la vida en los aspectos negativos de la vida (dolor, muerte, pérdida, decepción, conflicto, culpa, resentimiento, problemas no resueltos, errores potenciales, traición, cosas que pueden ir mal, etc.), mientras minimizan o niegan los aspectos positivos o optimistas.

Excesiva inhibición de la acción espontánea, sentimientos o comunicación, por lo general para crear un sentimiento de seguridad y pronóstico o para evitar cometer errores, la desaprobación de los demás, catástrofe y caos o la pérdida de control de los propios impulsos.

Inhibición emociona

La creencia profunda que uno debe esforzarse por encontrar unos estándares

Metas Inalcanzables internos de conducta y rendimientos muy elevados, normalmente para evitar las críticas 
Tabla 5

Taxonomía de Estilos de Afrontamiento Desadaptativos

\begin{tabular}{|c|c|c|}
\hline \multicolumn{3}{|c|}{ Estilos de Afrontamiento Desadaptativos } \\
\hline \multirow{6}{*}{ Sobrecompensación } & Agresión/Hostilidad & $\begin{array}{l}\text { Contraataca desafiando, abusando, } \\
\text { culpando, atacando o criticando a los } \\
\text { demás. }\end{array}$ \\
\hline & $\begin{array}{l}\text { Dominancial } \\
\text { Excesiva } \\
\text { autoafirmación }\end{array}$ & $\begin{array}{l}\text { Controla a los demás haciendo } \\
\text { referencia de manera directa al } \\
\text { cumplimiento de los objetivos }\end{array}$ \\
\hline & $\begin{array}{l}\text { Búsqueda de } \\
\text { reconocimientol } \\
\text { Búsqueda de status }\end{array}$ & $\begin{array}{l}\text { Sobrecompensa mediante el intento } \\
\text { de impresionar a los demás, un alto } \\
\text { rendimiento, status, búsqueda de } \\
\text { atención. }\end{array}$ \\
\hline & $\begin{array}{l}\text { Manipulación } \\
\text { Explotación }\end{array}$ & $\begin{array}{l}\text { Encuentra o satisface las necesidades } \\
\text { a través de la manipulación encubierta } \\
\text { de los demás, de manera seductora o } \\
\text { deshonestamente. }\end{array}$ \\
\hline & $\begin{array}{l}\text { Pasivo-agresivo } \\
\text { Rebelión }\end{array}$ & $\begin{array}{l}\text { Se comporta de forma abierta } \\
\text { complaciente mientras castiga a los } \\
\text { demás o se rebela de forma } \\
\text { encubierta demorándose, burlándose, } \\
\text { dejando de hacer }\end{array}$ \\
\hline & $\begin{array}{l}\text { Excesivo orden } \\
\text { Obsesionado }\end{array}$ & $\begin{array}{l}\text { Mantiene un estricto orden, mucho } \\
\text { autocontrol o altos niveles de } \\
\text { predictibilidad a través del orden y la } \\
\text { planificación; excesiva adherencia a la } \\
\text { rutina o ritual o excesiva precaución. } \\
\text { Dedica un tiempo desmesurado a } \\
\text { encontrar la mejor forma de lograr las } \\
\text { tareas o evitar resultados negativos. }\end{array}$ \\
\hline Mantenimiento & $\begin{array}{l}\text { Sumisión } \\
\text { Dependencia }\end{array}$ & $\begin{array}{l}\text { Centrado en los demás, cede, busca } \\
\text { la filiación, pasivo, dependiente, } \\
\text { sumiso, aferrado, evita el conflicto, } \\
\text { complace a los demás. }\end{array}$ \\
\hline \multirow{4}{*}{ Evitación } & $\begin{array}{l}\text { Retirado socialmente } \\
\text { Excesiva autonomía }\end{array}$ & $\begin{array}{l}\text { Afronta a través del aislamiento social, } \\
\text { desconexión, y la retirada. Puede } \\
\text { mostrarse, de manera exagerada, más } \\
\text { centrado en la independencia y } \\
\text { autosuficiencia que en estar implicado } \\
\text { con los demás. Algunas veces se } \\
\text { retira en actividades privadas como } \\
\text { ver excesivamente la televisión, leer, } \\
\text { jugar, trabajo solitario, etc. }\end{array}$ \\
\hline & $\begin{array}{l}\text { Búsqueda } \\
\text { Compulsiva de } \\
\text { Estimulación: }\end{array}$ & $\begin{array}{l}\text { Busca excitación o distracción a través } \\
\text { de la compra compulsiva, sexo, tomar } \\
\text { riesgos, actividades físicas, } \\
\text { novedades, etc. }\end{array}$ \\
\hline & $\begin{array}{l}\text { Tranquilización } \\
\text { adictiva } \\
\text { (Automedicación) }\end{array}$ & $\begin{array}{l}\text { Evita a través de adicciones que } \\
\text { implican el cuerpo, como el alcohol, } \\
\text { drogas, comer en exceso, } \\
\text { masturbación excesiva, etc. }\end{array}$ \\
\hline & $\begin{array}{c}\text { Retirado } \\
\text { Psicológicamente }\end{array}$ & $\begin{array}{l}\text { Afronta mediante la disociación, } \\
\text { negación, fantasía u otras formas } \\
\text { internas de escape psicológico. }\end{array}$ \\
\hline
\end{tabular}


Tabla 6

Paso a paso la Evaluación y Conceptualización en la TE

Evaluación e Identificación de los esquemas en la Terapia de Esquemas

Objetivos

Identificar los es-

quemas centrales

Unir los esquemas

con los problemas

actuales y de la

historia de vida

(experiencias de vida)

Identificación de los Esquemas

Hacer entrar al paciente en contacto con las emociones circundantes a estos esquemas

Identificar Estilos de Afrontamiento

Conceptualización del caso según TE

\section{Proceso/Técnicas}

El Presente: centrada en los problemas actuales y situaciones de la vida actual. Se intenta conectar los síntomas presentes con los problemas de la vida. El terapeuta empieza a hacer conexiones entre emociones, síntomas, problemas de la vida y los esquemas (denominados al inicio patrones). La entrevista se centra en la identificación de aquellos patrones de larga duración que caracterizan la vida actual de los pacientes. Los Patrones se hacen relevantes y se delimita su importancia en el funcionamiento psicológico. Se consideran Hipótesis de Esquemas a confirmar en la evaluación.

El Pasado: centrada en la historia de la vida donde se busca identificar los patrones aprendidos que actúan en la actualidad. Se realiza una evaluación evolutiva donde paciente y terapeuta exploran la historia de la vida a través de las experiencias y recuerdos que tienen una mayor significación, asociados a malestar y sufrimiento

Doble análisis: el primero centrado en los últimos 5 años donde se establece el estilo de funcionamiento y los patrones más característicos de la vida adulta del paciente en las distintas áreas de la vida (pareja, trabajo, amigos, ocio, expectativas, aspiraciones y deseos). El segundo, más evolutivo, empieza desde los primeros años de vida y continúa por la infancia y la adolescencia.

A nivel de proceso:

a) No sólo se busca conocer el clima emocional de crecimiento sino también se describen las relaciones significativas con los padres, familia extensa, amigos y los recuerdos traumáticos. Se intenta establecer los estilos de relación y cómo se van configurando los patrones de larga evolución y el estilo de funcionamiento.

b) se intentan delimitar las necesidades básicas no cubiertas, cómo el paciente las interpretaba e interpreta para obtener información del contenido del esquema

c) También es importante ir configurando cuál es el estilo de afrontamiento ante esas situaciones: evitación (rendirse), mantenimiento (aceptar) y sobre-compensación (luchar).

Una herramienta útil para facilitar la apertura en esta fase es el Inventario de la Historia de la Vida de Lazarus. También se pueden utilizar diarios personales, fotografías.

Evaluación de los esquemas: para ello debe administrarse el Cuestionario de Esquemas de Young (CEY). Una vez codificado se identifica la lista de esquemas para posteriormente realizar la devolución del CEY. Esta se realiza en una sesión o en distintas sesiones en función del paciente. El objetivo de devolución va más allá de describir los resultados del cuestionario si no que: (a) debe añadirse la información obtenida en las dos fases anteriores, buscando las coherencias e inconsistencias de la información aportada mediante la clarificación de contenidos; (b) debe empezarse la educación del concepto de esquemas y cómo funcionan; (c) debe proporcionarse ejemplos que faciliten un aumento de conciencia respecto las formas de dar significado al mundo y a sus experiencias ; (d) deben describirse los esquemas, etiquetándolos de forma significativa para el sujeto, ya sea poniéndole nombres o metaforizando el esquema.

Educación de los esquemas: se fomenta con material de auto-ayuda como la Guía del Cliente de la Terapia Cognitiva Centrada en los Esquemas o se recomienda el libro de autoayuda de la Terapia de esquemas "Reinventa tu Vida" (Young \& Klosko, 2001)

Activación de Esquemas: acceder a las emociones asociadas a los esquemas. Trabajo centrado en descubrir las emociones circundantes a los esquemas que a menudo son intensas y dolorosas.

Técnicas en la sesión (Imaginación). De manera exploratoria para unir las emociones que se sienten en la actualidad con las emociones del pasado y para explorar la continuidad de los esquemas (recuerdos familiares, interacciones significativas con los padres).

Fuera de la sesión: visualización de películas, lectura de libros, experimentos conductuales

Esta fase se caracteriza por aquellas estrategias que permiten identificar los estilos de afrontamiento desadaptativos que mantienen a los esquemas, ya sea reforzando, evitando o compensando.

Explorar los estilos de afrontamiento ante situaciones conflictivas, el estrés, los problemas no esperados e improvistos del día a día, las situaciones que se evitan.

Diferenciar las respuestas que se utilizan para afrontar algunas situaciones del día a día de aquellos patrones de respuestas de afrontamiento que son más independientes de la situación y que se utilizan de manera más generalizada en distintas situaciones y configuran por si mismas un estilo de afrontamiento.

Identificar el grado de éxito o fracaso de las estrategias de afrontamiento que utiliza el individuo. No se puede presuponer que todas las respuestas de afrontamiento perpetuarán los esquemas.

La fase de evaluación finaliza cuando el clínico puede realizar una conceptualización del caso en función de los estilos de funcionamiento cognitivo, conductual, emocional e interpersonal. Descripción del temperamento y recuerdos más significativos o traumáticos.

Explicarla al paciente, obtener feedback para ajustarla y que sea aceptada como guía de la fase de tratamiento. El paciente tiene que entender que esta va a ser la hoja de ruta del tratamiento entendiendo que todo esto es un proceso dinámico que se reevalúa durante el mismo.

Definir accesibilidad tratamiento TE, tipo de tratamiento TE (rasgos o Modos) o necesidad de tratamiento Eje I previo (en el caso adicciones, trastornos ansiedad).

Ajustar y clarificar objetivos del cambio, las características del cambio (no lineal, sino gradual con retrocesos, y necesidad de tolerar cierto grado de malestar emocional), y expectativas de cambio (proceso largo). 
Terapia de esquemas para los trastornos de personalidad y el intento de protocolarizarla mediante las guías esquematizadas para profesionales

Tal como hemos especificado en la introducción, es un ejercicio arriesgado realizar una aproximación de la TE trastorno por trastorno. Ya que ésta rehúye del diagnóstico de TP (i.e., categorial o dimensional) e intenta operacionalizarlos en función de esquemas, estilos de afrontamiento desadaptativos y modos de esquemas, en base a la experiencia subjetiva de la persona y del proceso de atribución de significados cognitivo-emocionales que presenta. El modelo de trabajo que se ha propuesto para los TP permite flexibilizar y adaptar las intervenciones a cada trastorno y sobretodo al hecho de que es frecuente encontrar en la clínica cotidiana diagnósticos comórbidos de Trastornos de la Personalidad o diagnósticos mixtos. No obstante, la TE a diferencia de otros modelos de psicoterapia ha desarrollado una serie de cuestionarios como el Cuestionario de Esquemas que permite no sólo evaluar clínicamente los constructos que propone el modelo y realizar una evaluación de resultados de la intervención, sino que permite la realización de investigaciones para poner a prueba las propuestas teóricas que van surgiendo de la asociación de esquemas, estilos de afrontamiento y modos de esquemas para cada TP.

Para diseñar las guías esquematizadas para profesionales se ha seguido el procedimiento que se explica a continuación. Para cada TP se han analizado los resultados de las investigaciones realizadas con los Cuestionarios de Esquemas (i.e., en su versiones original y la reducida). Así, en función de los resultados, se describirán los esquemas encontrados en base a resultados de investigación. En los casos en que no se han encontrado resultados empíricos, se describen las propuestas teóricas realizadas por diferentes autores que también se dedicaron al tema de los esquemas en cada Trastorno de la Personalidad. Puede consultarse para más detalles los trabajos de Bernsteisn (2002), Sperry (2005) y Arntz y Van Genderen (2009). Respecto a los Modos de Esquema cabe realizar una aclaración, la investigación en este campo está en sus fases iniciales, la mayoría de los resultados son producto de análisis de correlación entre los Modos de Esquemas y los Trastornos de la Personalidad, evaluados mediante entrevistas estructurada para los TP (Lobbestael, Van Vreeswijk \& Arntz, 2007; Lobbestael, Van Vreeswijk \& Arntz, 2008). Se incluyen los resultados encontrados en las primeras investigaciones debido a que pueden ser de mucha utilidad en el manejo de los casos.

Por último, basándose en los resultados de las investigaciones, en la literatura de la TE y la experiencia clínica de la aplicación de la TE, se realizará una aproximación a las dos fases de la intervención de la TE (i.e., evaluación e intervención). En la evaluación se describirán las estrategias más adecuadas para realizar una correcta conceptualización del caso. En la intervención se describirán el cambio cognitivo, emocional, relación terapéutica y conductual que se debe realizar de los principales esquemas encontrados en la investigación. Esta aproximación debe considerarse como tentativa y teórica. Cuando se utilice en la práctica clínica debe de entenderse como una aproximación posible, como una prueba de hipótesis a contrastar, y no como una manualización paso a paso. Por ello, es posible que los esquemas que se plantean para los TP no se encuentren en las personas que reciban tal diagnóstico. El objetivo que se pretende es acercar al lector cuáles son las estrategias de cambio cognitivo, emocional, interpersonal, y conductual para la mayor parte de esquemas que propone el modelo, y que las pueda adaptar en función de las características de los pacientes. Por este motivo, y una vez descriptos los esquemas más importantes y la estrategia de conceptualización, en la fase de cambio no se describirán todos los esquemas de manera exhaustiva en cada Trastorno de Personalidad. A continuación se definirán qué esquemas predominarían en cada trastorno de personalidad.

A partir de lo recopilado por los distintos autores citados en cada una de las guías esquematizadas que se presentan seguidamente, se decidió describir, dentro del Cluster A, el Esquema de Desconfianza/Abuso para el Trastorno de Personalidad Paranoide, el Esquema de Aislamiento Social para el TP Esquizoide, y los Esquemas de Desconfianza/Abuso y Vulnerabilidad al Peligro para el TP Esquizotípico. Dentro del Cluster B, para el TP Histriónico, los esquemas de Privación Emocional y Grandiosidad. En el TP Antisocial, los esquemas de Privación Emocional y Insuficiente Autocontrol. En el TP Límite y TP Narcisista describiremos la fase de cambio basada en los Modos de 
Esquemas. En el Cluster C, describiremos en el TP Evitativo, los Esquemas de Imperfección, Fracaso y Subyugación. En el TP Dependiente el esquema de Abandono y Dependencia.
En el TP Obsesivo Compulsivo describimos el cambio en los esquemas de Inhibición Emocional y Metas Inalcanzables. En el TP Pasivo-Agresivo describimos el cambio de Desconfianza y Fracaso.

Tabla 7

Guía esquematizada para el Trastorno de la Personalidad Paranoide

Para construir esta guía se tuvieron en cuenta las investigaciones de Loper (2003) y los aportes teóricos de Arntz y Van Genderen (2009)

\begin{tabular}{|c|c|c|c|}
\hline \multirow{3}{*}{$\begin{array}{l}\text { Esquemas } \\
\text { Predominantes }\end{array}$} & \multicolumn{2}{|c|}{ Desconfianza/Abuso } & $\begin{array}{l}\text { La expectativa que los otros le herirán, abusarán, humillarán, } \\
\text { burlarán, mentirán, manipularán. }\end{array}$ \\
\hline & \multicolumn{2}{|c|}{ Privación Emocional } & $\begin{array}{l}\text { La expectativa de que las propias necesidades emocionales de } \\
\text { afecto, empatia y cuidado no se encontrarán en los demás. }\end{array}$ \\
\hline & \multicolumn{2}{|c|}{ Aislamiento Social } & $\begin{array}{l}\text { El sentimiento de que uno está aislado del resto del mundo, } \\
\text { diferente de los demás y no participa o forma parte de un grupo o } \\
\text { comunidad. }\end{array}$ \\
\hline \multirow{3}{*}{$\begin{array}{l}\text { Modos } \\
\text { Esquemas }\end{array}$} & \multicolumn{2}{|c|}{ Niño Enfadado } & $\begin{array}{l}\text { Se siente intensamente enrabiado, frustrado o impaciente porque las } \\
\text { necesidades emocionales del niño vulnerable no se satisfacen. La } \\
\text { muestra de manera inapropiada. }\end{array}$ \\
\hline & \multicolumn{2}{|c|}{ Niño Enrabiado } & $\begin{array}{l}\text { Experimenta intensos sentimientos de rabia que da como resultado } \\
\text { herir o dañar a personas u objetos. Actúa impulsivamente y está } \\
\text { fuera de control por la rabia }\end{array}$ \\
\hline & \multicolumn{2}{|c|}{ Intimidación y Ataque } & $\begin{array}{l}\text { Hiere o daña directamente a los demás de una manera estratégica y } \\
\text { controlada, ya sea emocionalmente, fisicamente, sexualmente, } \\
\text { verbalmente o a través de actos antisociales. }\end{array}$ \\
\hline \multicolumn{4}{|c|}{ CURSO DE TRATAMIENTO } \\
\hline \multicolumn{2}{|c|}{ Objetivos Evaluación } & \multicolumn{2}{|r|}{ Proceso / Técnicas de la Evaluación y Conceptualización del caso } \\
\hline \multicolumn{2}{|c|}{ Inicio de la Intervención } & \multicolumn{2}{|c|}{$\begin{array}{l}\text { Centrarse en los problemas de la demanda y en las emociones. Progresivamente } \\
\text { ir explorando el impacto que tienen en su vida. Es necesario ir a su ritmo para } \\
\text { que adquiera confianza. Pacientes ponen a prueba el grado de confianza del } \\
\text { terapeuta, ponen trampas. Estar preparados y ser genuino ante las respuestas. }\end{array}$} \\
\hline \multicolumn{2}{|c|}{ Patrones del pasado } & \multicolumn{2}{|c|}{$\begin{array}{l}\text { Seguir la misma cautela pero espontaneidad en la realización de la historia de la } \\
\text { vida. Centrarse en los últimos } 5 \text { años si muestra una inhibición emocional. } \\
\text { Progresivamente ir hablando de las relaciones con los padres y grupos de } \\
\text { iguales. Identificar posibles carencias emocionales y "traumas. }\end{array}$} \\
\hline \multicolumn{2}{|c|}{ Identificación de Esquemas } & \multicolumn{2}{|c|}{$\begin{array}{l}\text { Administrar cuestionarios cuando el paciente se sienta cómodo y tenga una } \\
\text { minima confianza con el terapeuta. Realizar la devolución progresivamente, } \\
\text { explicando aquellas cosas que pueda ir comprendiendo emocionalmente. Revisar } \\
\text { el item de "abuso fisico, psicológico o sexual" y el de las carencias emocionales } \\
\text { básicas (cuidado y alimentación). Ser respetuoso ante la posibilidad de recuerdos } \\
\text { "traumáticos". A pesar de conocer su existencia, es importante que el paciente lo } \\
\text { exprese por sí mismo. }\end{array}$} \\
\hline \multicolumn{2}{|c|}{ Activación de Esquemas } & \multicolumn{2}{|c|}{$\begin{array}{l}\text { La activación de los esquemas en algunos casos puede ser difícil debido a la } \\
\text { existencia de recuerdos traumáticos. Es importante centrarse en la conexión } \\
\text { emocional presente-pasado y la manera de dar significado al mundo. Es útil en } \\
\text { algunos casos centrarse en la emoción de rabia. Seguir la metáfora "No destapes } \\
\text { el tarro de las esencias (recuerdos) si no estás seguro de que puedas (ayudar) } \\
\text { taparlo" }\end{array}$} \\
\hline \multicolumn{2}{|c|}{ Estrategias de Afrontamiento } & \multicolumn{2}{|c|}{$\begin{array}{l}\text { Conocer las estrategias de afrontamiento para hacer frente a la emoción de rabia, } \\
\text { y cómo se configuran los estilos conductuales que van mantenido a los } \\
\text { esquemas: Agresión-hostilidad, manipulación, alejamiento. } \\
\text { Temperamento: identificar impulsividad y agresividad. }\end{array}$} \\
\hline \multicolumn{2}{|c|}{ Conceptualización } & \multicolumn{2}{|c|}{$\begin{array}{l}\text { Identificar los aspectos del temperamento que influyen en la modulación de las } \\
\text { emociones y el aprendizaje de las estrategias de afrontamiento nuevas. }\end{array}$} \\
\hline \multicolumn{2}{|c|}{ Objetivos Cambio } & \multirow{2}{*}{\multicolumn{2}{|c|}{$\begin{array}{l}\text { Proceso / Técnicas Cambio de los Esquemas } \\
\text { Reducir la "hipervigilancia" de abuso o maltrato. Cambiar el exagerado punto de } \\
\text { vista "acerca de los demás* como intencionadamente malos, abusivos, } \\
\text { manipuladores o deshonestos. Cambiar el punto de vista de si mismo como } \\
\text { culpable e indefenso del abuso. No excusar al abusador. } \\
\text { Enseñar el espectro de maltrato. Trabajar sobre el pensamiento dicotómico. }\end{array}$}} \\
\hline \multirow{4}{*}{ Desconfianza/Abuso } & Cognitivo & & \\
\hline & Emocional & \multicolumn{2}{|c|}{$\begin{array}{l}\text { Recuperar recuerdos de abuso/humillación. Expresar rabia verbalmente y } \\
\text { fisicamente y al abusador en imaginación. Escribir cartas sobre necesidades } \\
\text { emocionales no cubiertas. No enviar las cartas. Encontrar un lugar seguro lejos } \\
\text { del abusador. }\end{array}$} \\
\hline & $\begin{array}{l}\text { Relación } \\
\text { Terapéutica }\end{array}$ & \multicolumn{2}{|c|}{$\begin{array}{l}\text { Ser completamente honesto y genuino con el paciente. Preguntar por la confianza } \\
\text { e intimidad de forma regular y discutir cualquier sentimiento negativo hacia el } \\
\text { terapeuta. Preguntar acerca de la vigilancia ("necesidad de control") en las } \\
\text { sesiones. Si es necesario no hacer trabajo experiencial, mientras se esté } \\
\text { construyendo la confianza. }\end{array}$} \\
\hline & Conductual & \multicolumn{2}{|c|}{$\begin{array}{l}\text { Gradualmente confiar en las personas, incrementar el nivel de intimidad, } \\
\text { compartir los secretos y memorias del abuso con compañeros (que no sean } \\
\text { abusivos). Buscar grupos de soporte con otras victimas. Elegir parejas o } \\
\text { compañeros no abusivos. No abusar de los demás. Castigar menos cuando las } \\
\text { personas cometan errores. Poner limites con las personas abusivas. Aprendizaje } \\
\text { del Manejo de emociones (rabia, disforia, ansiedad) y de Habilidades Sociales, } \\
\text { incluyendo la conducta asertiva. }\end{array}$} \\
\hline
\end{tabular}


Tabla 8

Guía esquematizada para el Trastorno de la Personalidad Esquizoide

Para construir esta guía se tuvieron en cuenta los aportes teóricos de Arntz y Van Genderen (2009)

PERFILES ESQUEMAS, ESTILOS AFRONTAMIENTO ESQUEMAS Y MODOS DE ESQUEMAS

\begin{tabular}{|c|l|l|}
\hline \multicolumn{2}{|c|}{ PERFILES ESQUEMAS, ESTILOS AFRONTAMIENTO ESQUEMAS Y MODOS DE ESQUEMAS } \\
\hline $\begin{array}{c}\text { Esquema } \\
\text { Predominante }\end{array}$ & Aislamiento Social & $\begin{array}{l}\text { El sentimiento de que uno está aislado del resto del mundo, } \\
\text { diferente de los demás y no participa o forma parte de un grupo } \\
\text { o comunidad. }\end{array}$ \\
\hline
\end{tabular}

CURSO DE TRATAMIENTO

Objetivos Evaluación y

Conceptualización Caso

Inicio de la Intervención

Identificación Esquemas

Patrones del pasado no les gusta. Pueden manifestar miedo o dificultades en sentir las emociones que son el nexo entre las situaciones actuales y los recuerdos del pasado. Empezar por escenas de grupo de pares donde se sienta diferente a los demás, puede ser de utilidad.

Identificar los aspectos temperamentales relacionados con la ansiedad, timidez e impulsividad que pueden influenciar en el manejo emocional y en el aprendizaje de estrategias de relación interpersonal y social. Plantear un cambio progresivo, preparando para las dificultades

\begin{tabular}{|c|}
\hline Objetivos Cambio \\
Terapéutico
\end{tabular}

Procesol Técnicas

\begin{tabular}{|c|c|c|}
\hline \multirow{4}{*}{$\begin{array}{c}\text { Aislamiento } \\
\text { Social }\end{array}$} & Cognitivo & $\begin{array}{l}\text { Cambiar el punto de vista de que uno es indeseable socialmente } \\
\text { Cambiar el exagerado punto de vista negativo respecto a la apariencia y las } \\
\text { habilidades sociales. Centrarse en las ventajas. } \\
\text { Minimizar las diferencias, aumentando las similitudes, con las otras personas. }\end{array}$ \\
\hline & Emocional & $\begin{array}{l}\text { Imaginación de memorias de ser diferente a los demás, rechazo, o aislamiento. } \\
\text { Ventilar emociones negativas hacia el grupo. } \\
\text { Recuperar recuerdos donde se sentía aceptado y había contacto social para reforzar } \\
\text { cambio. }\end{array}$ \\
\hline & $\begin{array}{c}\text { Relación } \\
\text { Terapéutica }\end{array}$ & $\begin{array}{l}\text { Ir con cuidado en las comparaciones, en el uso de metáforas o analogías, o el } \\
\text { sentido del humor en la terapia. Pueden ser no entendidas y causar una percepción } \\
\text { de mayor distanciamiento con el terapeuta y con los demás. Estar atento a las } \\
\text { situaciones dentro de la sesión en las que el paciente se pueda sentir diferente, } \\
\text { inferior o abrumado por la energía del terapeuta. Enfatizar y destacar los atributos } \\
\text { sociales positivos. Confrontar la evitación de las situaciones sociales. }\end{array}$ \\
\hline & Conductual & $\begin{array}{l}\text { Vencer la evitación: listar las situaciones temidas y que se evitan. Aplicar estrategias } \\
\text { de exposición graduada. Aprendizaje de habilidades que faciliten la competencia } \\
\text { social: entrenamiento en manejo de Emociones y Resolución Problemas. } \\
\text { Habilidades sociales y conducta asertiva. La inclusión en un grupo de Terapia para } \\
\text { problemas interpersonales puede ser útil. Progresivamente intentar ir haciendo } \\
\text { amigos, participar en actividades de la comunidad. Es frecuente que necesiten } \\
\text { soporte adicional en esta última área, por parte de otros profesionales. }\end{array}$ \\
\hline
\end{tabular}


Tabla 9

Guía esquematizada para el Trastorno de la Personalidad Esquizotípico

Para construir esta guía se tuvieron en cuenta los aportes teóricos de Arntz y Van Genderen (2009)

\begin{tabular}{|c|c|c|c|}
\hline \multirow{3}{*}{$\begin{array}{l}\text { Esquemas } \\
\text { Predominantes }\end{array}$} & \multicolumn{2}{|c|}{ Desconfianza/Abuso } & $\begin{array}{l}\text { La expectativa que los otros le herirán, abusarán, humillarán, } \\
\text { burlarán, mentirán, manipularán. }\end{array}$ \\
\hline & \multicolumn{2}{|c|}{ Aislamiento Social } & $\begin{array}{l}\text { Sentimiento de que uno está aislado del mundo, diferente de } \\
\text { los demás y no participa de un grupo. }\end{array}$ \\
\hline & \multicolumn{2}{|c|}{ Vulnerabilidad al Peligro } & $\begin{array}{l}\text { Miedo exagerado a que una "fortuita/azarosa" catástrofe } \\
\text { ocurra en cualquier momento y que no será capaz de } \\
\text { prevenirla. }\end{array}$ \\
\hline \multicolumn{4}{|c|}{ CURSO DE TRATAMIENTO } \\
\hline \multicolumn{2}{|c|}{$\begin{array}{l}\text { Objetivos Evaluación y } \\
\text { Conceptualización Caso }\end{array}$} & & Proceso / Técnicas \\
\hline \multicolumn{2}{|c|}{ Inicio de la Intervención } & $\begin{array}{l}\text { La presen } \\
\text { disminució } \\
\text { un Estado } \\
\text { 2003). La } \\
\text { de la psic } \\
\text { SIPS/SOP } \\
\text { en la TCC } \\
\text { 2004). Si } \\
\text { puede pl } \\
\text { focalizará } \\
\text { autonomía } \\
\text { aislamient } \\
\text { problemas }\end{array}$ & $\begin{array}{l}\text { de un TP Esquizotípico, correctamente diagnosticado y una } \\
\text { en el GAF de } 30 \text { puntos en el último año, puede considerarse } \\
\text { ental de Alto Riesgo de Desarrollar una Psicosis (Young et al. } \\
\text { aluación de EMAR debe realizarse con una evaluación clínica } \\
\text { atología y una entrevista clínica estructurada: CAARMS y/o } \\
\text { Una vez realizada, la intervención psicológica debe basarse } \\
\text { ra el Eje I o Terapia Cognitiva para EMAR (French \& Morrison, } \\
\text { ta evoluciona bien, no se da una transición a la psicosis y } \\
\text { earse una intervención basada en el autoconcepto. Se } \\
\text { las dificultades y problemas no resueltos en el área de } \\
\text { g., Fracaso) y relaciones interpersonales (e.g., desconfianza, } \\
\text { ocial e imperfección) (Addington \& Tran, 2009). Enunciar los } \\
\text { funcionamiento que presentan en el dia a dia }\end{array}$ \\
\hline \multicolumn{2}{|c|}{ Identificación Esquemas } & \multicolumn{2}{|c|}{$\begin{array}{l}\text { Administrar Cuestionario de Esquemas para perfilar la visión del sí mismo y } \\
\text { cómo puede estar involucrada en los problemas de funcionamiento en las } \\
\text { áreas de la vida. }\end{array}$} \\
\hline \multicolumn{2}{|c|}{ Patrones del pasado } & \multicolumn{2}{|c|}{$\begin{array}{l}\text { Les es muy difícil abrirse y explicar sus experiencias y relaciones. } \\
\text { Reformular con cuidado para mostrar comprensión y empatía. }\end{array}$} \\
\hline \multicolumn{2}{|c|}{ Activación Esquemas } & \multicolumn{2}{|c|}{$\begin{array}{l}\text { A veces no conviene hacer trabajo de imaginación de entrada, utilizar otras } \\
\text { estrategias como la música, fotografias para activar los esquemas dentro } \\
\text { de la sesión e identificar emociones y significados experienciales. } \\
\text { Empezar por situaciones que evitan para ir venciendo las resistencias. } \\
\text { Hacer imaginación con los ojos abiertos y mirando fijamente a un punto del } \\
\text { despacho. }\end{array}$} \\
\hline \multicolumn{2}{|c|}{ Estrategias Afrontamiento } & \multicolumn{2}{|c|}{$\begin{array}{l}\text { Definir el déficit funcional que presenta. La no adquisición de ciertas } \\
\text { habilidades perpetúa los esquemas. Será necesario facilitar el aprendizaje } \\
\text { de estas habilidades. Conocer las situaciones que evita, sobretodo el } \\
\text { consumo de drogas y delimitar las estrategias de evitación emocional } \\
\text { (Tranquilización adictiva) y si el consumo es utilizado como reforzador } \\
\text { positivo (confianza ante una situación estresante). }\end{array}$} \\
\hline \multicolumn{2}{|c|}{ Conceptualización } & \multicolumn{2}{|c|}{$\begin{array}{l}\text { Definir si el temperamento es pasivo o miedoso para delimitar el repertorio } \\
\text { conductual. Delimitar el rol de los padres en desarrollo de los esquemas. }\end{array}$} \\
\hline \multicolumn{2}{|c|}{ Objetivos Cambio Terapéutico } & \multicolumn{2}{|r|}{ Proceso / Técnicas } \\
\hline \multirow{4}{*}{ Desconfianza/Abuso } & Cognitivo & \multicolumn{2}{|c|}{$\begin{array}{l}\text { Reducir la "hipervigilancia" de abuso o maltrato. Enseñar el espectro de } \\
\text { desconfianza y maltrato. Tonalidades de gris, en vez de todo o nada. } \\
\text { Cambiar el punto de vista "acerca de los demás" como intencionadamente } \\
\text { malos, abusivos, manipuladores o deshonestos, y "de uno mismo" como } \\
\text { culpable del abuso o de estar indefenso. No excusar al abusador. }\end{array}$} \\
\hline & Emocional & \multicolumn{2}{|c|}{$\begin{array}{l}\text { Recuperar memorias de desconfianza, humillación u abuso. Expresar rabia } \\
\text { verbal y físicamente. Escribir cartas sobre necesidades emocionales no } \\
\text { cubiertas. No enviar las cartas!. }\end{array}$} \\
\hline & $\begin{array}{l}\text { Relación } \\
\text { Terapéutica }\end{array}$ & \multicolumn{2}{|c|}{$\begin{array}{l}\text { Ser completamente honesto y genuino con el paciente. Preguntar por la } \\
\text { confianza e intimidad de forma regular - discutir cualquier sentimiento } \\
\text { negativo hacia el terapeuta. Preguntar acerca de la vigilancia ("necesidad } \\
\text { de control") en las sesiones. Si es necesario no hacer trabajo experiencial, } \\
\text { mientras se esté construyendo la confianza. }\end{array}$} \\
\hline & Conductual & \multicolumn{2}{|c|}{$\begin{array}{l}\text { Necesitaran soporte de otros profesionales en función del déficit funcional. } \\
\text { Esto les ayudará a confiar en las personas. Aprendizaje del Manejo de } \\
\text { emociones (rabia, disforia, ansiedad) y de Habilidades Sociales. Dar } \\
\text { oportunidades de relación que sean confiables. Cambiar las conductas } \\
\text { extravagantes mediante modelado de conducta }\end{array}$} \\
\hline \multirow{4}{*}{$\begin{array}{l}\text { Vulnerabilidad al } \\
\text { peligro y a la } \\
\text { enfermedad }\end{array}$} & Cognitivo & \multicolumn{2}{|c|}{$\begin{array}{l}\text { Hacer balance de pros y contras del miedo y peligros en el presente y en el } \\
\text { pasado. Retar la percepción exagerada de daño, peligro y enfermedad. }\end{array}$} \\
\hline & Emocional & \multicolumn{2}{|c|}{$\begin{array}{l}\text { Imaginación: dialogar con el/los padres "miedoso, fóbico" y "que } \\
\text { sobreprotegia". Visualizar resultados seguros en las situaciones cotidianas }\end{array}$} \\
\hline & $\begin{array}{l}\text { Relación } \\
\text { Terapéutica }\end{array}$ & \multicolumn{2}{|c|}{$\begin{array}{l}\text { Confrontar la evitación, dar calma, consolar racionalmente. Reforzar } \\
\text { cambios y animar al cambio. }\end{array}$} \\
\hline & Condu & \multicolumn{2}{|c|}{$\begin{array}{l}\text { Construir una jerarquía de situaciones temidas. Exponerse gradualmente a } \\
\text { estas situaciones, vencer la evitación. Manejo de la ansiedad y el miedo. }\end{array}$} \\
\hline
\end{tabular}


Tabla 10

Guía esquematizada para el Trastorno Histriónico de la Personalidad

Para construir esta quía se tuvieron en cuenta los aportes teóricos de Arntz y Van Genderen (2009)

\begin{tabular}{|c|c|c|c|}
\hline \multicolumn{4}{|c|}{ PERFILES ESQUEMAS, ESTILOS AFRONTAMIENTO ESQUEMAS Y MODOS DE ESQUEMAS } \\
\hline \multirow{4}{*}{$\begin{array}{c}\text { Esquemas } \\
\text { Predominantes }\end{array}$} & \multicolumn{2}{|c|}{ Abandono } & $\begin{array}{l}\text { Percepción de inestabilidad o poca seguridad de que se dispone de } \\
\text { soporte y relación con los demás. Expectativa acerca de que los demás lo } \\
\text { abandonarán. }\end{array}$ \\
\hline & \multicolumn{2}{|c|}{$\begin{array}{l}\text { Privación } \\
\text { Emocional }\end{array}$} & $\begin{array}{l}\text { Expectativa de que las propias necesidades emocionales de afecto, } \\
\text { empatía y cuidado no se encontrarán en los demás. }\end{array}$ \\
\hline & \multicolumn{2}{|c|}{ Grandiosidad } & $\begin{array}{l}\text { La creencia de que uno es superior a los demás, que le da derecho a } \\
\text { privilegios y derechos especiales; o no tener que limitarse por las reglas de } \\
\text { reciprocidad que guían la interacción social habitual. }\end{array}$ \\
\hline & \multicolumn{2}{|c|}{$\begin{array}{l}\text { Insuficiente } \\
\text { Autocontrol }\end{array}$} & $\begin{array}{l}\text { Dificultad persistente o negativa de emplear/o usar el suficiente autocontrol } \\
\text { y tolerancia a la frustración para conseguir sus propios objetivos, o } \\
\text { contener/reprimir de forma excesiva sus emociones e impulsos. }\end{array}$ \\
\hline $\begin{array}{l}\text { Modos } \\
\text { Esquemas }\end{array}$ & \multicolumn{2}{|c|}{ Niño Impulsivo } & $\begin{array}{l}\text { Se comporta según sus deseos no nucleares o impulsos de manera egoísta } \\
\text { o poco controlada para conseguirlos a su manera, muchas veces tiene } \\
\text { problemas a la hora de retrasar las gratificaciones inmediatas. }\end{array}$ \\
\hline \multicolumn{4}{|r|}{ CURSO DE TRATAMIENTO } \\
\hline \multicolumn{2}{|c|}{$\begin{array}{l}\text { Objetivos Evaluación y } \\
\text { Conceptualización Caso }\end{array}$} & & Proceso/ Técnicas \\
\hline \multicolumn{2}{|c|}{ Inicio de la Intervención } & $\begin{array}{l}\text { Ident } \\
\text { Acep } \\
\text { aten } \\
\text { adec }\end{array}$ & $\begin{array}{l}\text { car los posibles problemas, emociones y posibles indicadores de esquemas. } \\
\text { Ir la exageración y la externalización de la causa de sus problemas. Estar } \\
\text { a las estrategias manipuladoras de seducción para manejarlas de manera } \\
\text { ada y poder ir construyendo una relación de confianza y seguridad. }\end{array}$ \\
\hline \multicolumn{2}{|c|}{ Identificación Esquemas } & $\begin{array}{l}\text { La a } \\
\text { misn } \\
\text { funci } \\
\text { estra }\end{array}$ & $\begin{array}{l}\text { inistración del Cuestionario de Esquemas, ayuda a perfilar la visión del sí } \\
\text { del paciente y cómo esta puede estar involucrada en los problemas de } \\
\text { namiento en las áreas de la vida. Explicar el concepto de esquema y } \\
\text { gias de afrontamiento. }\end{array}$ \\
\hline \multicolumn{2}{|c|}{ Pasado } & $\begin{array}{l}\text { Activ } \\
\text { relac } \\
\text { confi }\end{array}$ & $\begin{array}{l}\text { recuerdos del pasado relacionados con carencias, no cuidado en las } \\
\text { nes con los padres. Delimitar el papel de los grupos de iguales en la } \\
\text { rración esquemas. }\end{array}$ \\
\hline \multicolumn{2}{|c|}{ Activación Esquemas } & $\begin{array}{l}\text { Ir de } \\
\text { de c } \\
\text { reen } \\
\text { com }\end{array}$ & $\begin{array}{l}\text { acio, aparecerán recuerdos con alta carga emocional. No iniciar estrategias } \\
\text { nbio, favorecer la aceptación de las emociones y del dolor. Es importante } \\
\text { ladrar las sesiones de imaginación para favorecer los elementos de la } \\
\text { ensión cognitiva de cómo funcionan los esquemas. }\end{array}$ \\
\hline \multicolumn{2}{|c|}{ Estrategias Afrontamiento } & $\begin{array}{l}\text { Defin } \\
\text { valor } \\
\text { y/o }\end{array}$ & $\begin{array}{l}\text { las principales estrategias de afrontamiento pero de manera específica } \\
\text { la búsqueda de reconocimiento y/o búsqueda del status, la Manipulación } \\
\text { olotación, y la Retirada Psicológica. }\end{array}$ \\
\hline \multicolumn{2}{|c|}{ Conceptualización } & Ident & ar el rol del temperamento impulsivo, ansioso y búsqueda de aprobación. \\
\hline \multicolumn{2}{|c|}{$\begin{array}{l}\text { Objetivos Cambio } \\
\text { Terapéutico }\end{array}$} & \multicolumn{2}{|r|}{ Proceso/ Técnicas } \\
\hline \multirow{4}{*}{$\begin{array}{l}\text { Privación } \\
\text { emocional }\end{array}$} & Cognitivo & $\begin{array}{l}\text { Cam } \\
\text { eg } \\
\text { esc } \\
\text { En } \\
\text { Apre } \\
\text { en }\end{array}$ & $\begin{array}{l}\text { ar el sentido exagerado de que las personas actuarán o están actuando } \\
\text { tamente o están actuado privando al paciente (e.g., no los quieren, no los } \\
\text { chan, no los entienden, no los atienden, no los miman, no los cuidan). } \\
\text { ñar grados de grises en los niveles de carencia y de cuidado emocional. } \\
\text { der y modificar expectativa de que "las necesidades emocionales no se } \\
\text { ntrarán o no serán satisfactorias" en las relaciones de intimidad con otros. }\end{array}$ \\
\hline & Emocional & & $\begin{array}{l}\text { sar cólera y dolor al padre que privó en imaginación. Preguntar en } \\
\text { inación a los padres para encontrar las necesidades emocionales. } \\
\text { ir cartas, expresando dolor y necesidades emocionales no cubiertas. No } \\
\text { rr. Trabajo "dos sillas": Esquema "privación" vs. "Adulto Sano" : Expresar } \\
\text { sidades emocionales no cubiertas y modelar su expresión. Tres sillas si } \\
\text { da psicológica: } 1 \text { fase: "Adulto Sano" vs. "protector alejado". Pedir permiso } \\
\text { r Privación. 2. "Protector Alejado" vs. "Adulto Sano" vs. "Privación" }\end{array}$ \\
\hline & $\begin{array}{l}\text { Relación } \\
\text { Terapéutica }\end{array}$ & & $\begin{array}{l}\text { r una atmósfera cuidadosa de empatía, consejo y atención. Ayudar a los } \\
\text { ntes a expresar los sentimientos de privación sin hiperreaccionar o } \\
\text { dando silencio. Ayudar al paciente a aceptar las limitaciones del terapeuta y } \\
\text { ar alguna privación, mientras aprecian el cuidado que obtienen. } \\
\text { s relaciones con las memorias de recuerdos tempranas (infancia). }\end{array}$ \\
\hline & Conductual & & $\begin{array}{l}\text { parejas que los cuiden. Preguntar de forma adecuada a las parejas para } \\
\text { las necesidades emocionales cubiertas. No hiperreaccionar a los niveles } \\
\text { ivación con cólera. No alejarse o aislarse cuando los demás los hieran. }\end{array}$ \\
\hline \multirow{4}{*}{ Grandiosidad } & Cognitivo & & $\begin{array}{l}\text { el punto de vista de ser especial, con derechos especiales. Estimular la } \\
\text { tía hacia los demás -principio de reciprocidad. Señalar las consecuencias } \\
\text { tivas de la grandiosidad. }\end{array}$ \\
\hline & Emocional & Acce & er a la cara vulnerable: los esquemas subyacentes. \\
\hline & $\begin{array}{l}\text { Relación } \\
\text { Terapéutica }\end{array}$ & & $\begin{array}{l}\text { de actuar de forma grandiosa balancear las propias necesidades con las de } \\
\text { emás: "Seguir las reglas". }\end{array}$ \\
\hline & Conductual & & $\begin{array}{l}\text { tar la grandiosidad, "ser especial"- poner límites. Dar soporte a la } \\
\text { bilidad. No dar soporte al estatus, poder, etc. }\end{array}$ \\
\hline
\end{tabular}


Tabla 11

Guía esquematizada para el Trastorno Antisocial de la Personalidad

Para construir esta guía se tuvieron en cuenta las investigaciones de Loper (2003) y los aportes teóricos de Arntz y Van Genderen (2009)

\section{PERFILES ESQUEMAS, ESTILOS AFRONTAMIENTO ESQUEMAS Y MODOS DE ESQUEMAS}

\begin{tabular}{|c|c|c|}
\hline \multirow{5}{*}{$\begin{array}{c}\text { Esquemas } \\
\text { Predominantes }\end{array}$} & Desconfianza & $\begin{array}{l}\text { La expectativa que los otros le herirán, abusarán, humillarán, burlarán, mentirán, } \\
\text { manipularán, aprovecharán }\end{array}$ \\
\hline & Abandono & $\begin{array}{l}\text { Percepción de inestabilidad o poca seguridad de que se dispone de soporte y } \\
\text { relación con los demás. Incluye la expectativa acerca de que los demás } \\
\text { irremediablemente les abandonarán. }\end{array}$ \\
\hline & $\begin{array}{l}\text { Privación } \\
\text { Emocional }\end{array}$ & $\begin{array}{l}\text { La expectativa de que las propias necesidades emocionales de afecto, empatía } \\
\text { y cuidado no se encontrarán en los demás. }\end{array}$ \\
\hline & Grandiosidad & $\begin{array}{l}\text { Creencia de que uno es superior a los demás, que le da derecho a privilegios y } \\
\text { derechos especiales; o no tener que limitarse por las reglas de reciprocidad que } \\
\text { guian la interacción social habitual. }\end{array}$ \\
\hline & $\begin{array}{l}\text { Insuficiente } \\
\text { Autocontrol }\end{array}$ & $\begin{array}{l}\text { Dificultad persistente o negativa de usar el suficiente autocontrol y tolerancia a la } \\
\text { frustración para conseguir sus propios objetivos, o contener/reprimir de forma } \\
\text { excesiva sus emociones e impulsos. }\end{array}$ \\
\hline \multirow{2}{*}{$\begin{array}{l}\text { Modos } \\
\text { Esquemas }\end{array}$} & $\begin{array}{c}\text { Excesiva } \\
\text { Compensación }\end{array}$ & $\begin{array}{l}\text { Se siente y se comporta de manera desmesuradamente especial, agresiva, } \\
\text { dominante, competitiva, arrogante, condescendiente, devalúa a los demás, } \\
\text { hipercontrolado, controlador, rebelde, manipulador, explotador, búsqueda de } \\
\text { atención o de la posición social. }\end{array}$ \\
\hline & $\begin{array}{l}\text { Padre } \\
\text { Castigador }\end{array}$ & $\begin{array}{l}\text { Siente que uno mismo o los demás merecen el castigo o la culpa y a menudo } \\
\text { actúa según estos sentimientos culpando, castigado o abusando hacia uno } \\
\text { mismo (e.g., autolesiones). Este estado de ánimo se refiere al estilo en que las } \\
\text { reglas fueron aplicadas, y no tanto a la naturaleza de las reglas. }\end{array}$ \\
\hline \multicolumn{3}{|r|}{ CURSO DE TRATAMIENTO } \\
\hline \multicolumn{2}{|c|}{$\begin{array}{l}\text { Objetivos Evaluación y } \\
\text { Conceptualización Caso }\end{array}$} & Proceso/ Técnicas \\
\hline \multicolumn{2}{|c|}{ Inicio de la Intervención } & $\begin{array}{l}\text { Es difícil que acepten terapia psicológica. Es más factible en contextos de tipo } \\
\text { judicial que sea factible realizar algún tipo de aproximación o si están deprimidos. } \\
\text { Estar preparados para responder a la manipulación, mentiras, la transgresión de } \\
\text { los limites. }\end{array}$ \\
\hline \multicolumn{2}{|c|}{ Identificación Esquemas } & $\begin{array}{l}\text { En la administración del Cuestionario de Esquemas, tienden a mentir y a } \\
\text { magnificar y minimizar la información. Ir con cautela en su interpretación. }\end{array}$ \\
\hline \multicolumn{2}{|c|}{ Patrones del Pasado } & $\begin{array}{l}\text { Es muy difícil que expresen su historia experiencial. Emocionalmente no } \\
\text { sintónicos. }\end{array}$ \\
\hline \multicolumn{2}{|c|}{ Activación Esquemas } & $\begin{array}{l}\text { Inicialmente puede ser factible no hacer activación esquemas. Es necesaria una } \\
\text { sólida confianza. Estar preparados para emociones intensas de rabia y cólera. }\end{array}$ \\
\hline \multicolumn{2}{|c|}{ Estrategias Afrontamiento } & $\begin{array}{l}\text { Definir principales estrategias de afrontamiento, sobretodo la sobre-compensación: } \\
\text { Agresión u Hostilidad, Dominancia, y Manipulación o Explotación. }\end{array}$ \\
\hline \multicolumn{2}{|c|}{ Conceptualización } & Identificar el rol del temperamento impulsivo y la búsqueda de sensaciones. \\
\hline \multicolumn{2}{|c|}{$\begin{array}{l}\text { Objetivos Cambio } \\
\text { Terapéutico }\end{array}$} & Proceso/ Técnicas \\
\hline \multirow{4}{*}{$\begin{array}{l}\text { Privación } \\
\text { emocional }\end{array}$} & Cognitivo & $\begin{array}{l}\text { Cambiar el sentido exagerado de que las personas actuarán o están actuando } \\
\text { egoístamente o están actuado al paciente (e.g., no lo quieren, no lo escuchan, no } \\
\text { lo entienden, no lo atienden, no lo miman, no lo cuidan). Enseñar grados de grises } \\
\text { en los niveles de carencia y de cuidado emocional. Aprender y modificar la } \\
\text { expectativa acerca de "las necesidades emocionales no se encontrarán o no serán } \\
\text { satisfactorias" en las relaciones de intimidad con los demás. }\end{array}$ \\
\hline & Emocional & $\begin{array}{l}\text { Expresar cólera y dolor al padre que privó en imaginación. Preguntar en } \\
\text { imaginación a los padres para encontrar las necesidades emocionales. Escribir } \\
\text { cartas para cada persona, expresando dolor y necesidades emocionales no } \\
\text { cubiertas. No enviar. Trabajo "dos sillas": esquema "privación" vs. "Adulto Sano": } \\
\text { Expresar necesidades emocionales no cubiertas y modelar su expresión. Tres } \\
\text { sillas si retirada psicológica: primera fase: "Adulto Sano" vs. "protector alejado". } \\
\text { Pedir permiso hablar Privación. Segunda fase: "Protector Alejado" vs. "Adulto } \\
\text { Sano" vs. "Privación". }\end{array}$ \\
\hline & $\begin{array}{l}\text { Relación } \\
\text { Terapéutica }\end{array}$ & $\begin{array}{l}\text { Proveer una atmósfera cuidadosa- empatía, consejo y atención. Ayudar a los } \\
\text { pacientes a expresar los sentimientos de privación sin hiperreaccionar o } \\
\text { guardando silencio. Ayudar al paciente a aceptar las limitaciones del terapeuta y } \\
\text { tolerar alguna privación, mientras aprecian el cuidado que obtienen. Unir las } \\
\text { relaciones con las memorias de recuerdos tempranas (infancia). }\end{array}$ \\
\hline & Conductual & $\begin{array}{l}\text { Elegir parejas que les cuiden. Preguntar de forma adecuada a las parejas para } \\
\text { tener las necesidades emocionales cubiertas. No hiperreaccionar a los niveles de } \\
\text { privación con cólera. No alejarse o aislarse cuando los demás les hieran. }\end{array}$ \\
\hline \multirow{4}{*}{$\begin{array}{l}\text { Insuficiente } \\
\text { autocontrol }\end{array}$} & Cognitivo & Enseñar a valorar gratificaciones a largo plazo versus gratificaciones a corto plazo. \\
\hline & Emocional & $\begin{array}{l}\text { Explorar la conexión con los esquemas (dominio separación rechazo) y el afecto a } \\
\text { través de la imaginación. }\end{array}$ \\
\hline & $\begin{array}{l}\text { Relación } \\
\text { Terapéutica }\end{array}$ & $\begin{array}{l}\text { Ser firme, poner límites. Establecer un gradiente de consecuencias asociadas a } \\
\text { saltarse límites. Empalizar con necesidades emocionales no cubiertas. }\end{array}$ \\
\hline & Conductual & $\begin{array}{l}\text { Enseñar autodisciplina a través de tareas estructuradas. Enseñar técnicas de auto- } \\
\text { control de las emociones. }\end{array}$ \\
\hline
\end{tabular}


Tabla 12

Guía esquematizada para el Trastorno de la Personalidad Límite I

Para construir esta guía se tuvieron en cuenta los aportes teóricos de Arntz y Van Genderen (2009), Tineo y Young (2006) y Tineo, Alén, Chajét, Chajét \& Sá (2006)

\section{PERFILES MODOS DE ESQUEMAS}

Se siente solo, débil, solitario, triste, no comprendido, no apoyado, imperfecto, necesitado o privado emocionalmente, abrumado o agobiado, incompetente, duda de sí mismo, necesitado,

Niño Vulnerable incapaz o indefenso, desesperado, miedoso, angustiado, preocupado, toman represalias en contra, inútil, no querido, antipático, perdido, sin dirección, frágil, frustrado, oprimido, impotente o ineficaz, ausente, excluido o pesimista.

Corta, aísla o cerca las necesidades y los sentimientos, se separa emocionalmente de las personas y rechaza su ayuda, se siente reservado o introvertido, alejado, distraído,

Protector Aislado desconcertado o separado, despersonalizado, vacío o aburrido, sigue distrayéndose, se autotranquiliza o se auto- estimula en actividades ya sea de manera compulsiva o en exceso. Puede adoptar una postura cínica, reservada o pesimista para evitar invertir en personas o actividades

Niño Enfadado

Se siente intensamente enfadado, enrabiado o enfurecido, furioso, frustrado, impaciente porqué las necesidades emocionales (o físicas) nucleares del niño vulnerable no se satisfacen.

Siente que uno mismo o los demás merecen el castigo o la culpa y a menudo actúa según estos

Padre Castigador sentimientos culpando, castigado o abusando hacía uno mismo (e.g., autolesiones). Este estado de ánimo se refiere al estilo en que las reglas fueron aplicadas, y no tanto a la naturaleza de las reglas.

Alimenta, valida y afirma al modo del niño vulnerable. Pone límites a los modos del niño enfadado e impulsivo. Promueve y apoya al modo el niño saludable. Combate y eventualmente sustituye a los modos de afrontamiento desadaptativos. Neutraliza o modera a los modos de los padres desadaptativos. Proporciona las funciones apropiadas del adulto tales como trabajar, roles de padres y relaciones con la familia, tomar responsabilidades y comprometerse. Sigue actividades de placer de los adultos tales como el sexo, los intereses intelectuales, estéticos y culturales. El mantenimiento de la salud y de las actividades atléticas.

\section{OBJETIVOS Y ENCUADRE DEL TRATAMIENTO}

\section{Objetivos y \\ Encuadre}

Encuadre de

tratamiento

Objetivos

Tratamiento

Tratamiento

Fase Previa o Inicial (6-12 sesiones)

\section{Proceso/ Técnicas}

Dos sesiones terapia a la semana de 50-60 minutos el primer año. Una sesión a partir del segundo año. Un año y medio a tres años de tratamiento.

Alta implicación y accesibilidad del terapeuta. Plantearse la posibilidad de contacto mediante teléfono móvil, fuera de sesión de una manera limitada (situaciones de crisis definidas) para el paciente.

Necesidad de supervisión de casos y soporte a través de grupo de pares.

La terapia pasará por los distintos objetivos y mantiene la filosofia de tratamiento que proponemos. Las distintas fases que se explican pueden variar del orden que proponemos en la siguiente tabla de intervención. Aunque mantendriamos las estrategias cognitivas, conductuales, emocionales e interpersonales para conseguir el cambio de los esquemas.

Ayudar al paciente a incorporar el Modo de Adulto Sano, modelado a través del terapeuta a través de:

Empatizar con y proteger al Niño Abandonado

Ayudar al Niño Abandonado a dar y recibir amor

Luchar en contra y borrar o minimizar El Padre Castigador

Reconectar el Niño Enfadado y Impulsivo para expresar las emociones y necesidades de un modo apropiado, reafirmando los derechos básicos de la infancia

Tranquilizar y gradualmente reemplazar el Protector Aislado

Ver al paciente como un niño vulnerable

Realmente necesitado, no codicioso

El terapeuta también tiene derechos

No culpar cuando se sienta frustrado

Desarrollo paralelo del niño

Respeto mutuo y sinceridad

Estos objetivos forman parte de la intervención, son importantes pero lo más importantes es ir construyendo una adecuada relación terapéutica con el paciente

Evaluación Diagnóstica y psicométrica de Trastorno Límite de la Personalidad (Arntz \& Van Genderen, 2009)

Explicar el Trastorno Limite de manera racional en modos de esquemas y cuáles son las fases de intervención. Dar lectura del libro de autoayuda de Reinventa tu vida.

Intervención en el Eje I. Tratar la comorbilidad de adicciones, trastornos de ansiedad, depresión, etc previamente al inicio de la Terapia de Esquemas

Una vez finalizada esta fase inicial se procede al inicio de la Intervención en TE. 


\begin{tabular}{|c|c|c|}
\hline & & CURSO DEL TRATAMIENTO \\
\hline Fas & Inicial & Procesol Técnicas \\
\hline $\begin{array}{l}\text { Fase I: Vin } \\
\text { Manejo de }\end{array}$ & $\begin{array}{l}\text { culación y } \\
\text { Emociones }\end{array}$ & $\begin{array}{l}\text { Esta fase en muchos casos es la misma que la anterior, si el proceso diagnóstico de } \\
\text { TLP está bien establecido y sino es necesario un tratamiento de Eje I, y puede } \\
\text { considerarse un repaso de la primera explicación del TP Límite según el modelo. }\end{array}$ \\
\hline $\begin{array}{l}\text { Socializ } \\
\text { concepte }\end{array}$ & $\begin{array}{l}\text { ación y } \\
\text { alización }\end{array}$ & $\begin{array}{l}\text { Socializar y preparar para la intervención. Empatizar con los problemas que le ocurra. } \\
\text { Discutir los objetivos de la terapia. Preguntar por las reacciones emocionales. Hablar de } \\
\text { la historia de la vida, incluyendo la infancia. Explicar otra vez los Modos de Esquemas }\end{array}$ \\
\hline $\begin{array}{l}\text { Tranquilizar y } \\
\text { Reemplazar el }\end{array}$ & Cognitivas & $\begin{array}{l}\text { Ayudar al paciente a reconocer las señales del Protector Aislado. Explicar el modo de } \\
\text { desarrollo de la infancia y la empatia con su valor de adaptación. Revisión pros y los } \\
\text { contras de separarse en el presente, como un adulto. Práctica de diálogos (con dos } \\
\text { sillas técnica) entre Protector Aislado y Adulto Sano. Pedir permiso para poder hablar y } \\
\text { acceder con el Niño Vulnerable }\end{array}$ \\
\hline $\begin{array}{l}\text { Protector } \\
\text { Aislado }\end{array}$ & Imaginación & $\begin{array}{l}\text { Niño Vulnerable. Proceso: ¿Qué está ocurriendo? ¿Qué ves (todos los sentidos? } \\
\text { ¿Quién está contigo? ¿Cuántos años tienes? ¿Cómo te sientes? ¿Qué necesitas? } \\
\text { Continuar con la imaginación dependiendo de los modos de emergen en la imagen. } \\
\text { Traiga terapeuta en imagen como Adulto Sano para demostrar las respuestas de } \\
\text { adaptación a cada modo }\end{array}$ \\
\hline $\begin{array}{l}\text { Curar al Niño } \\
\text { Vulnerable }\end{array}$ & $\begin{array}{l}\text { Relación } \\
\text { terapéutica }\end{array}$ & $\begin{array}{l}\text { A través de la reactuación parental limitada ayudar a curar al Niño Vulnerable } \\
\text { Validación de las necesidades y sentimientos } \\
\text { Cuidar y proporcionar una base estable } \\
\text { Fomento de la confianza y de un guía. Ser capaz de elogiar los avances y los cambios. } \\
\text { Fomentar la reciprocidad y auto-revelación por parte del terapeuta }\end{array}$ \\
\hline Estrategias de & Cognitivas & Diario de Esquemas y Tarjeta Recordatorio \\
\hline $\begin{array}{l}\text { Manejo } \\
\text { Emocional y } \\
\text { Aprendizaje } \\
\text { Habilidades }\end{array}$ & Conductuales & $\begin{array}{l}\text { Aprendizaje de estrategias de regulación emocional y de Tolerancia al Malestar } \\
\text { emocional. Práctica de la Meditación o Conciencia Plena (Mindfulness). Entrenamiento } \\
\text { en Asertividad. Fomentar la realización de Actividades Placenteras, ya sean de ocio y/o } \\
\text { tiempo libre. }\end{array}$ \\
\hline Fase II. Cambio & M. Esquemas & Proceso/ Técnicas \\
\hline & Cognitivas & $\begin{array}{l}\text { Educar acerca de las necesidades universales y los sentimientos. Reatribución del } \\
\text { rechazo de la infancia a problemas o temas de los padres. Enfatizar los éxitos y las } \\
\text { cualidades positivas }\end{array}$ \\
\hline $\begin{array}{l}\text { Combatir el } \\
\text { Padre } \\
\text { Castigador }\end{array}$ & & $\begin{array}{l}\text { Reatribución en imaginación del Padre Castigador. Dos partes. Primera paciente como } \\
\text { adulto. Paciente reevalúa la situación como adulto. Segunda Paciente como niño (el } \\
\text { paciente experimenta la intervención del adulto como niño. Recibe soporte y ayuda por } \\
\text { parte del adulto. }\end{array}$ \\
\hline & Emocionales & $\begin{array}{l}\text { Diálogos en el Trabajo de la Silla Vacia: } 2 \text { sillas. Padre Castigador vs. Adulto Sano; Tres } \\
\text { sillas. Protector Aislado vs. Padre Castigador vs. Adulto sano. Primero: Terapeuta como } \\
\text { niño (experimenta perspectiva del otro en la escena) y Paciente como otra persona } \\
\text { (situación original). Padre o Madre. Segundo, terapeuta como otra persona y paciente } \\
\text { como niño (reevaluando la situación). }\end{array}$ \\
\hline $\begin{array}{l}\text { Reconec } \\
\text { Enfadado } \\
\text { la Relación }\end{array}$ & $\begin{array}{l}\text { tar el Niño } \\
\text { mpulsivo en } \\
\text { Terapéutica }\end{array}$ & $\begin{array}{l}\text { Poner límites cuando sea abusivo o destructivo. Ventilar las emociones. Empalizar con } \\
\text { los esquemas subyacentes. Prueba de realidad: punto vista real vs. Punto vista } \\
\text { exagerado. Compartir el impacto y la reacción personal ante la rabia, cólera o enfado. } \\
\text { Practicar la conducta asertiva. }\end{array}$ \\
\hline Poner & imites & $\begin{array}{l}\text { Las dificultades en los límites: } \\
\text { Contacto fuera de las sesiones } \\
\text { Cambios de visitas o ausencias en las visitas } \\
\text { Expectativas poco realistas de la relación terapéutica (comportarse "como si" } \\
\text { fuera un padre) } \\
\text { Conductas autodestructivas, parasuicidas y suicidas } \\
\text { Conductas amenazantes hacia el terapeuta o "amenazas de romper objetos } \\
\text { Proceso gradual de tres fases de graduación } \\
\text { A. Se indica el traspaso del límite, con empatia, y centrándose en el hecho. Se pide } \\
\text { que pare. . } \\
\text { B. Se indica traspaso del límite, con graduación sentimientos del terapeuta hacia el } \\
\text { paciente, se anuncia consecuencia. } \\
\text { C. Se indica traspaso del límite, con graduación sentimientos del terapeuta hacia el } \\
\text { paciente, se aplica consecuencia. }\end{array}$ \\
\hline Manejo & le Crisis & $\begin{array}{l}\text { Cuando se dan las crisis es un buen momento para realizar estrategias de cambio de } \\
\text { esquemas, ya que el modo protector aislado no está presente y las emociones } \\
\text { aparecen. Es necesario establecer limites que el paciente debe seguir las instrucciones } \\
\text { del terapeuta ante las crisis suicidas, o la terapia deberá terminar } \\
\text { Ante una crisis: incrementar la frecuencia de contacto, permitir llamadas telefónicas. } \\
\text { Identificar el modo de esquemas que se activa. Proporcionar estrategias para manejar } \\
\text { los esquemas en cada Modo. Evaluar los pensamientos e ideación suicida en cada } \\
\text { contacto. No descartar estrategias como medicación, tratamiento grupal, contacto con } \\
\text { personas significativas. Si es necesario, ir a urgencias o a hospitalización parcial. }\end{array}$ \\
\hline Fase III. A & utonomía & $\begin{array}{l}\text { Desarrollar relaciones saludables. Proceso de individuación: Seguir las inclinaciones } \\
\text { naturales, realizar el proyecto vital que se ajuste a sus necesidades. Terminar la } \\
\text { terapia de manera progresiva y Mantener contactos después de terminar la } \\
\text { intervención }\end{array}$ \\
\hline
\end{tabular}


Tabla 14

Guía esquematizada para el Trastorno de la Personalidad Narcisista

\begin{tabular}{|c|c|c|}
\hline \multicolumn{3}{|r|}{ PERFILES DE ESQUEMAS Y MODOS DE ESQUEMAS } \\
\hline \multirow{4}{*}{$\begin{array}{l}\text { Esquemas } \\
\text { Predominantes }\end{array}$} & $\begin{array}{l}\text { Privación } \\
\text { Emocional }\end{array}$ & $\begin{array}{l}\text { La expectativa de que el propio deseo de tener un grado normal de soporte emocional no será } \\
\text { satisfecho de modo adecuado en los demás. }\end{array}$ \\
\hline & Imperfección & $\begin{array}{l}\text { Sentimiento de que es defectuoso, malo, no querido, inferior o inválido en aspectos } \\
\text { importantes; o que sería no querido por los demás si se muestra tal como es. }\end{array}$ \\
\hline & Grandiosidad & $\begin{array}{l}\text { La creencia de que uno es superior a los demás, que le da derecho a privilegios y derechos } \\
\text { especiales; o no tener que limitarse por las reglas de reciprocidad que guian la interacción } \\
\text { social habitual. }\end{array}$ \\
\hline & tros Esquemas & $\begin{array}{l}\text { Búsqueda de Aprobación, Adicciones y búsqueda estimulación (Estrategias evitación) Metas } \\
\text { inalcanzables. Subyugación, Desconfianza }\end{array}$ \\
\hline \multirow{4}{*}{$\begin{array}{l}\text { Modos } \\
\text { Esquemas }\end{array}$} & Niño Solitario & $\begin{array}{l}\text { Se sienten niños solitarios, valorados cuando son ensalzados por sus padres. No se sienten } \\
\text { queridos y adorables. Se sienten vacios. Es el modo vulnerable que encontramos en los } \\
\text { pacientes narcisistas, no se sienten especiales, sino como "la media, como los demás", que } \\
\text { significa rechazo y que son socialmente inaceptables. Se activa por la pérdida de validación, } \\
\text { posición y estatus. }\end{array}$ \\
\hline & $\begin{array}{l}\text { Exaltación de } \\
\text { uno mismo }\end{array}$ & $\begin{array}{l}\text { Excesiva sobre- compensación al sentirse especial, importante, competitivo, buscando } \\
\text { atención y estatus. Se siente superior, crítico con los demás, sin mostrar ninguna empatia, } \\
\text { envidioso. Estilos de afrontamiento agresión y hostilidad, dominancia, búsqueda de } \\
\text { reconocimiento, y manipulación o explotación. Es el modo por defecto. }\end{array}$ \\
\hline & $\begin{array}{l}\text { La Auto- } \\
\text { tranquilización } \\
\text { al Aislarse }\end{array}$ & $\begin{array}{l}\text { Manifiesta intereses solitarios, conductas compulsivas, se distrae etc. Serían formas de } \\
\text { evitación de los esquemas. Este modo ayuda a cortar las emociones que surgen cuando esta } \\
\text { solo o en ausencia de fuentes de validación. Evitaría la activación del niño solitario, y sentir las } \\
\text { emociones dolorosas de este modo. }\end{array}$ \\
\hline & Adulto Sano & $\begin{array}{l}\text { Alimenta, valida y afirma al modo del niño vulnerable. Pone límites a los modos del niño } \\
\text { enfadado e impulsivo. Promueve y apoya al modo el niño saludable. Combate y eventualmente } \\
\text { sustituye a los modos de afrontamiento desadaptativos. Neutraliza o modera los modos de los } \\
\text { padres desadaptativos. Proporciona funciones apropiadas del adulto como trabajar, roles de } \\
\text { padres y relaciones con la familia, tomar responsabilidades y comprometerse. Sigue } \\
\text { actividades de placer de los adultos como el sexo, intereses intelectuales, estéticos y } \\
\text { culturales. El mantenimiento de la salud y las actividades atléticas. }\end{array}$ \\
\hline \multicolumn{3}{|r|}{ OBJETIVOS Y ENCUADRE DEL TRATAMIENTO } \\
\hline \multicolumn{3}{|c|}{ Procesol Técnicas } \\
\hline Evaluación & \multicolumn{2}{|c|}{$\begin{array}{l}\text { Observar las conductas del paciente en las sesiones. Delimitar los problemas actuales y de su historia (rechazo } \\
\text { o represalias por parte de los demás, vacio, respuestas al fracaso, la necesidad de validación, culpabilizar a los } \\
\text { demás). No utilizar estrategias de evaluación si hay recuerdos de privación, soledad o devaluación. En los } \\
\text { Cuestionarios de Esquemas, tienden a puntuar muy bajo en Grandiosidad y Metas Inalcanzables, y alto en el } \\
\text { Cuestionario de Esquemas de Compensación. }\end{array}$} \\
\hline Filosofía de Tratamiento & \multicolumn{2}{|c|}{$\begin{array}{l}\text { to Aumentar progresivamente la vulnerabilidad y al mismo tiempo utilizar menos las estrategias de compensación y } \\
\text { la evitación. Enfocado a las relaciones con los demás y a la relación terapéutica. }\end{array}$} \\
\hline $\begin{array}{l}\text { Objetivos } \\
\text { Tratamiento }\end{array}$ & \multicolumn{2}{|c|}{$\begin{array}{l}\text { "Exaltación de uno mismo". Ayudar a dejar y superar la necesidad de aprobación y validación por parte de los } \\
\text { meás, de la misma manera que el Niño Solitario permite un cuidado más genuino. Ayuda cuando está en e } \\
\text { modo "Tranquilización al Aislarse" a dejar las conductas podo adaptativas a favor de un verdadero cuidado. }\end{array}$} \\
\hline Principales Estrategias & \multicolumn{2}{|c|}{$\begin{array}{l}\text { 1. Establece y lista sus actuales quejas como elemento para comenzar las intervenciones. } \\
\text { 2. Cuidadosamente y con tacto confronta el estilo condescendiente o retador } \\
\text { 3. Limites y derechos: No dejes pasar de largo cuando no respete tus derechos como terapeuta. Hazlo cor } \\
\text { 4. Mucho tacto, centrado en la conducta específica o el hecho. } \\
\text { 4. Muestra tu propia vulnerabilidad } \\
\text { 5. Con delicadeza introduce el concepto de Niño Solitario } \\
\text { 6. Refuerza la vulnerabilidad mientras alejas al Modo "Exaltación de uno mismo" y "Auto-Tranquilización a } \\
\text { 7. Aislarse" } \\
\text { 8. Creara diálogos entre los modos (imaginación y silla vacía) } \\
\text { 9. Une el Niño Solitaria con las actuales relaciones íntimas } \\
\text { 10. Generaliza los cambios que ocurren en la sesión. Introducir técnicas modificación estilo de vida. }\end{array}$} \\
\hline $\begin{array}{l}\text { Técnicas } \\
\text { Relación } \\
\text { Terapéutica }\end{array}$ & \multicolumn{2}{|c|}{$\begin{array}{l}\text { Crear un ambiente donde se sienta cuidado, respetado, entendido y valorado sin ser perfecto o especial. Ser } \\
\text { capaz de empatizar con el terapeuta sin que el terapeuta tenga que ser especial o perfecto. La relación } \\
\text { terapéutica va a ser clave para aceptar una atención sincera o de ser cuidado, confrontando la conducta de } \\
\text { aprobación y el criticismo hacia el terapeuta sin devaluar, corregir las valoraciones hacia el terapeuta de } \\
\text { "egoísta" o "querer controlarlo" e identificar sentimientos de soledad y vacío. }\end{array}$} \\
\hline $\begin{array}{l}\text { Técnicas } \\
\text { Específicas } \\
\text { Experienciales }\end{array}$ & \multicolumn{2}{|c|}{$\begin{array}{l}\text { Identificar sentimientos de soledad y vulnerabilidad en imaginación de escenas con los padres. Expresar la falta } \\
\text { de cuidado, las elevadas expectativas y el criticismo. Conectar con las emociones. A nivel de modos: el Adulto } \\
\text { sano cuida al Niño Solitario, reta a la "Exaltación de uno mismo" y minimiza a "Auto-Tranquilización al Aislarse" }\end{array}$} \\
\hline $\begin{array}{l}\text { Técnicas } \\
\text { Específicas } \\
\text { Cognitivas }\end{array}$ & \multicolumn{2}{|c|}{$\begin{array}{l}\text { Reformular pensamiento dicotómico "Ser especial vs. Ser Ignorado". Reformular y reestructuración cognitiva de } \\
\text { ser minusvalorado por los demás y expectativas de perfeccionismo. Enfatizar desventajas de trabajar, estatus, } \\
\text { "pensar que es especial", "de hacer lo que uno quiere con los demás" }\end{array}$} \\
\hline $\begin{array}{l}\text { Técnicas } \\
\text { Específicas } \\
\text { Conductuales }\end{array}$ & \multicolumn{2}{|c|}{$\begin{array}{l}\text { Cambiar las conductas evitativas y de tranquilización: adicciones, búsqueda estimulación. Sustituir intimidad. } \\
\text { Reduce el tiempo dedicado al estatus, incrementando el tiempo a las relaciones con los demás. Reduce la } \\
\text { energía de obtener cosas de los demás, aprender a dar, cuidar. }\end{array}$} \\
\hline $\begin{array}{l}\text { Técnicas } \\
\text { Específicas } \\
\text { Intimidad }\end{array}$ & \multicolumn{2}{|c|}{$\begin{array}{l}\text { Cambiar la tendencia a la idealización de las parejas. Énfasis en la perfección, apariencia más que en dar y } \\
\text { recibir cuidado, cariño y soporte. Tendencia a ver la pareja como reflejo de uno mismo }\end{array}$} \\
\hline
\end{tabular}


Tabla 15

Guía esquematizada para el Trastorno de la Personalidad por Dependencia

Para construir esta guía se tuvieron en cuenta las investigaciones de Gude, Hoffart, Hedley \& Rø Ø (2004), Simos (2002) y los aportes teóricos de Arntz y Van Genderen (2009)

\section{PERFILES ESQUEMAS, ESTILOS AFRONTAMIENTO ESQUEMAS Y MODOS DE ESQUEMAS}

\begin{tabular}{|c|c|c|c|}
\hline \multirow{4}{*}{$\begin{array}{l}\text { Esquemas } \\
\text { Predominantes }\end{array}$} & \multicolumn{2}{|c|}{ Dependencia } & $\begin{array}{l}\text { Creencia de que uno es incapaz de realizar sus responsabilidades } \\
\text { diarias de forma competente, sin ayuda de los demás. }\end{array}$ \\
\hline & \multicolumn{2}{|c|}{ Abandono } & $\begin{array}{l}\text { Percepción de inestabilidad o poca seguridad de que se dispone de } \\
\text { soporte y relación con los demás. Incluye la expectativa acerca de que } \\
\text { los demás irremediablemente les abandonarán. }\end{array}$ \\
\hline & \multicolumn{2}{|c|}{ Imperfección } & $\begin{array}{l}\text { Sentimiento que uno es defectuoso, malo, no querido, inferior o } \\
\text { inválido en aspectos importantes; o que no sería querido por los } \\
\text { demás si se muestra tal como es. }\end{array}$ \\
\hline & \multicolumn{2}{|c|}{ Subyugación } & $\begin{array}{l}\text { Excesivamente entregados al control de los demás porque se siente } \\
\text { cohesionado: para evitar la cólera, represalias o abandono }\end{array}$ \\
\hline \multirow{3}{*}{ Modos Esquemas } & \multicolumn{2}{|c|}{$\begin{array}{l}\text { Niño } \\
\text { Vulnerable }\end{array}$} & $\begin{array}{l}\text { Se siente solo, débil, solitario, triste, no comprendido, no apoyado, } \\
\text { imperfecto, necesitado o privado emocionalmente, abrumado o } \\
\text { agobiado, incompetente, duda de sí mismo, necesitado, incapaz o } \\
\text { indefenso, desesperado, miedoso, angustiado, preocupado, }\end{array}$ \\
\hline & \multicolumn{2}{|c|}{$\begin{array}{l}\text { Rendición } \\
\text { Sumisa }\end{array}$} & $\begin{array}{l}\text { Se comporta de manera pasiva, servil, sumisa, búsqueda de la } \\
\text { aprobación, se desprecia ante los demás, alejándose por miedo a } \\
\text { problemas u conflictos o al rechazo }\end{array}$ \\
\hline & \multicolumn{2}{|c|}{$\begin{array}{l}\text { Niño } \\
\text { Indisciplinado }\end{array}$} & $\begin{array}{l}\text { Se comporta según sus deseos no nucleares o impulsos de manera } \\
\text { egoista o poco controlada para conseguirlos a su manera y asi muchas } \\
\text { veces tiene problemas a la hora de retrasar las gratificaciones } \\
\text { inmediatas o a corto plazo. }\end{array}$ \\
\hline \multicolumn{4}{|c|}{ CURSO DE TRATAMIENTO } \\
\hline $\begin{array}{l}\text { Objetivos Evaluación y } \\
\text { Conceptualización Caso }\end{array}$ & \multicolumn{3}{|r|}{ Procesol Técnicas } \\
\hline Inicio de la Intervención & \multicolumn{3}{|c|}{$\begin{array}{l}\text { Delimitar los problemas de autonomía y en las relaciones y su estilo. Evitar ir deprisa y caer en } \\
\text { la tentativa ante los problemas de la vida cotidiana de dar consejos, solucionar rápidamente sus } \\
\text { problemas. }\end{array}$} \\
\hline Patrones del Pasado & \multicolumn{3}{|c|}{$\begin{array}{l}\text { Ir con cuidado al realizar la historia de la vida. Establecer las situaciones de la infancia en las } \\
\text { que simplemente obedecia, de la adolescencia "en las que no opinaba y seguia". Delimitar las } \\
\text { emociones, enfado, humillación, rabia y culpa. Ajustar las reformulaciones a las palabras del } \\
\text { paciente. }\end{array}$} \\
\hline Identificación Esquemas & \multicolumn{3}{|c|}{$\begin{array}{l}\text { La administración de cuestionarios ayuda a delimitar los esquemas. Es necesario ante la } \\
\text { devolución de los esquemas que entiendan intelectualmente y emocionalmente que son el } \\
\text { objetivo de cambio. Utilizar metáforas. }\end{array}$} \\
\hline Activación Esquemas & \multicolumn{3}{|c|}{$\begin{array}{l}\text { Explicar de manera clara y especifica. Manifiestan miedo a experimentar emociones en sesión. } \\
\text { Ante su vergüenza, utilizar previamente estrategias como la música, películas. }\end{array}$} \\
\hline Estrategias Afrontamiento & \multicolumn{3}{|c|}{$\begin{array}{l}\text { Identificar las estrategias de evitación y de mantenimiento de los esquemas. Definir el déficit de } \\
\text { habilidades en las relaciones sociales e intimas. }\end{array}$} \\
\hline Conceptualización & \multicolumn{3}{|c|}{ Delimitar el tipo de temperamento: ansioso, evitativo y el papel de la introversión. } \\
\hline $\begin{array}{l}\text { Objetivos Cambio } \\
\text { Terapéutico }\end{array}$ & \multicolumn{3}{|r|}{ Proceso/ Técnicas } \\
\hline \multirow{4}{*}{ Dependencia } & Cognitivo & & $\begin{array}{l}\text { ar el punto de vista del paciente que se cree incapaz de funcionar en el } \\
\text { sin una constante asistencia de las otras personas. Cambiar el punto de } \\
\text { lel paciente de que no puede confiar en sus propias decisiones o juicios } \\
\text { situaciones cotidianas. }\end{array}$ \\
\hline & Emocional & & $\begin{array}{l}\text { ar cólera a los padres a través de la imaginación por la excesiva } \\
\text { upación y por socavar lo juicios }\end{array}$ \\
\hline & $\begin{array}{c}\text { Relación } \\
\text { Terapéutica }\end{array}$ & & $\begin{array}{l}r \text { intentos del paciente de determinar un rol dependiente. Estimularlo a } \\
\text { sus propias decisiones y elecciones. Elogiar el juicio y el progreso. }\end{array}$ \\
\hline & Conductual & & $\begin{array}{l}\text { er asignaciones graduadas para afrontar estas tareas cotidianas solo, } \\
\text { esidad de asistencia de los demás. }\end{array}$ \\
\hline \multirow{4}{*}{ Abandono } & Cognitivo & & $\begin{array}{l}\text { ar punto de vista exagerado de que las otras personas les van a dejar, se } \\
\text { arán, se apartarán de ellos, o se comportarán de manera impredecible. } \\
\text { iar expectativas poco realistas de que las personas significativas } \\
\text { lan estar siempre disponibles y ser consistentes. Reducir el estar } \\
\text { dos de manera exagerada o en exclusiva de estar seguros de que sus } \\
\text { añeros están alli. }\end{array}$ \\
\hline & Emocional & & $\begin{array}{l}\text { nación para reexperienciar memorias del padre impredecible e inestable } \\
\text { padre que murió o dejó el hogar. Expresar cólera hacia el padre inestable } \\
\text { predecible. Trabajo del "niño profundo" para ayudar al paciente a cuidar } \\
\text { abandonado. }\end{array}$ \\
\hline & $\begin{array}{l}\text { Relación } \\
\text { Terapéutica }\end{array}$ & & $\begin{array}{l}\text { peuta llega a ser fuente transicional de seguridad y estabilidad. El } \\
\text { uta corrige las distorsionas acerca de la probabilidad del abandono del } \\
\text { te. Ayudar al paciente a aceptar las salidas, las vacaciones y la } \\
\text { onibilidad del terapeuta sin reaccionar de forma exagerada. }\end{array}$ \\
\hline & Conductual & & $\begin{array}{l}\text { compañeros que son estables y comprometidos. No excesivos celos, } \\
\text {, etc. Gradualmente aprender a tolerar estar solo. Aprender a tolerar } \\
\text { ntes seguros y estables. }\end{array}$ \\
\hline
\end{tabular}


Tabla 16

Guía esquematizada para el Trastorno de la Personalidad Evitativo

Para construir esta guía se tuvieron en cuenta las investigaciones de Loper (2003), Sperry (2004), Arntz (2008), Simos (2002), Jovev y Jackson (2001) y Ball y Cecero (2001)

\begin{tabular}{|c|c|c|}
\hline \multicolumn{3}{|c|}{ PERFILES ESQUEMAS, ESTILOS AFRONTAMIENTO ESQUEMAS Y MODOS DE ESQUEMAS } \\
\hline \multirow{4}{*}{$\begin{array}{l}\text { Esquemas } \\
\text { Predominantes }\end{array}$} & Imperfección & $\begin{array}{l}\text { El sentimiento que uno es defectuoso, malo, no querido, inferior o inválido en } \\
\text { aspectos importantes; o que uno sería no querido de forma significativa por los } \\
\text { demás si se muestra tal como es. }\end{array}$ \\
\hline & Fracaso & $\begin{array}{l}\text { La creencia que uno ha fracasado, inevitablemente fallará o que } \\
\text { fundamentalmente resulta inadecuado en relación a los grupos de iguales, en } \\
\text { áreas de rendimiento (escuela, carrera, deportes, etc.) }\end{array}$ \\
\hline & $\begin{array}{l}\text { Aislamiento } \\
\text { Social }\end{array}$ & $\begin{array}{l}\text { El sentimiento de que uno está aislado del resto del mundo, diferente de los } \\
\text { demás y no participa o forma parte de un grupo o comunidad. }\end{array}$ \\
\hline & Subyugación & $\begin{array}{l}\text { Excesivamente entregado o abandonado al control de los demás porque se } \\
\text { siente cohesionado: usualmente para evitar la cólera, represalias o el } \\
\text { abandono }\end{array}$ \\
\hline \multirow{5}{*}{$\begin{array}{l}\text { Modos } \\
\text { Esquemas }\end{array}$} & Niño Vulnerable & $\begin{array}{l}\text { Se siente solo, débil, solitario, triste, no comprendido, imperfecto, abrumado o } \\
\text { agobiado, incompetente, duda de si mismo, necesitado, incapaz o indefenso, } \\
\text { desesperado, miedoso, angustiado, preocupado. }\end{array}$ \\
\hline & Protector Aislado & $\begin{array}{l}\text { Corta, aísla o cerca las necesidades y los sentimientos, se separa } \\
\text { emocionalmente de las personas y rechaza su ayuda }\end{array}$ \\
\hline & Rendición Sumisa & $\begin{array}{l}\text { Se comporta de manera pasiva, sumisa, búsqueda de la aprobación, se } \\
\text { desprecia ante los demás, alejándose por miedo a problemas u conflictos o al } \\
\text { rechazo }\end{array}$ \\
\hline & Padre Castigador & $\begin{array}{l}\text { Siente que uno mismo o los demás merecen el castigo o la culpa y a menudo } \\
\text { actúa según estos sentimientos culpando, castigado }\end{array}$ \\
\hline & Niño Indisciplinado & $\begin{array}{l}\text { Se comporta según sus deseos no nucleares o impulsos de manera egoísta o } \\
\text { poco controlada para conseguirlos a su manera. }\end{array}$ \\
\hline \multicolumn{3}{|r|}{ CURSO DE TRATAMIENTO } \\
\hline \multicolumn{2}{|c|}{$\begin{array}{l}\text { Objetivos Evaluación y } \\
\text { Conceptualización Caso }\end{array}$} & Proceso / Técnicas \\
\hline \multicolumn{2}{|c|}{ Inicio de la Intervención } & $\begin{array}{l}\text { Delimitar los problemas de autonomía y en las relaciones y su estilo. Ir a su } \\
\text { ritmo. }\end{array}$ \\
\hline \multicolumn{2}{|c|}{ Patrones del Pasado } & $\begin{array}{l}\text { Ir con cuidado a realizar la historia de la vida. Ajustar las reformulaciones a las } \\
\text { palabras del paciente. }\end{array}$ \\
\hline \multicolumn{2}{|c|}{ Identificación Esquemas } & $\begin{array}{l}\text { La administración de cuestionarios ayuda a delimitar los esquemas. Utilizar } \\
\text { metáforas. }\end{array}$ \\
\hline \multicolumn{2}{|c|}{ Activación Esquemas } & $\begin{array}{l}\text { Explicar de manera clara y específica. Manifiestan miedo a experimentar } \\
\text { emociones en sesión. Si excesiva vergüenza, utilizar previamente estrategias } \\
\text { tales como la música, películas. }\end{array}$ \\
\hline \multicolumn{2}{|c|}{ Estrategias Afrontamiento } & Identificar las estrategias de evitación y de mantenimiento de los esquemas. \\
\hline \multicolumn{2}{|c|}{ Conceptualización } & $\begin{array}{l}\text { Delimitar el tipo de temperamento: ansioso, evitativo y el papel de la } \\
\text { introversión. }\end{array}$ \\
\hline \multicolumn{2}{|c|}{ Objetivos Cambio Terapéutico } & Proceso/ Técnicas \\
\hline \multirow{4}{*}{ Imperfección } & Cognitivo & $\begin{array}{l}\text { Cambiar el punto de vista de uno mismo como malo, no querido, imperfecto-- } \\
\text { centrarse en las ventajas, minimizar los defectos. }\end{array}$ \\
\hline & Emocional & Sacar la cólera hacia los padres críticos. Dialogar con el esquema crítico. \\
\hline & Relación Terapéutica & $\begin{array}{l}\text { No juzgar, crear un ambiente de aceptación. Compartir la menor debilidad del } \\
\text { terapeuta. Felicitar de forma adecuada al paciente. }\end{array}$ \\
\hline & Conductual & $\begin{array}{l}\text { Elegir parejas que acepten las cosas. No hiperreaccionar al criticismo. Auto- } \\
\text { descubrir más que vencer la culpa. No sobrecompensar (e.g., a través de } \\
\text { hacer excesivo énfasis en el estatus). }\end{array}$ \\
\hline \multirow{4}{*}{ Fracaso } & Cognitivo & $\begin{array}{l}\text { Retar el punto de vista del paciente que es inherentemente inepto, estúpido. } \\
\text { Reatribución de fracaso a esquema de mantenimiento. Destacar los éxitos y } \\
\text { las habilidades. Fijar expectativas realistas. }\end{array}$ \\
\hline & Emocional & $\begin{array}{l}\text { Acceder a las memorias de los padres, profesores, etc. críticos o de dar poco } \\
\text { soporte. También a las comparaciones con los hermanos, o expectativas poco } \\
\text { realistas. Imaginación para vencer la evitación ante situaciones de "hacer } \\
\text { cosas" y "rendimiento". }\end{array}$ \\
\hline & Relación Terapéutica & Apoyar el éxito. Fijar expectativas realistas. Dar estructura, límites. \\
\hline & Conductual & $\begin{array}{l}\text { Graduar tareas para llevar a cabo nuevos retos. Fijar límites, crear estructuras } \\
\text { para vencer la demora y enseñar auto-disciplina. }\end{array}$ \\
\hline \multirow{4}{*}{ Subyugación } & Cognitivo & $\begin{array}{l}\text { Retar las exageradas consecuencias negativas de expresar las necesidades } \\
\text { (e.g., castigo, represalias, abandono). }\end{array}$ \\
\hline & Emocional & $\begin{array}{l}\text { Expresar cólera y afirmar los derechos al padre controlador a través de la } \\
\text { imaginación. }\end{array}$ \\
\hline & Relación Terapéutica & $\begin{array}{l}\text { No controlar en exceso. Estimular al paciente a tomar decisiones. } \\
\text { Señalar la conducta respetuosa- identificando la cólera. }\end{array}$ \\
\hline & Conductual & $\begin{array}{l}\text { Seleccionar compañeros que no sean controladores. Gradualmente hacer } \\
\text { valer o afirmar las "propias" necesidades ante los demás. Aprender las } \\
\text { inclinaciones naturales y actuar según ellas. }\end{array}$ \\
\hline
\end{tabular}


Tabla 17

Guía esquematizada para el Trastorno de la Personalidad Obsesivo-Compulsivo

Para construir esta guía se tuvieron en cuenta las investigaciones de Sperry (2004), Arntz (2008) y Jovev y Jackson (2001)

\begin{tabular}{|c|c|c|}
\hline \multicolumn{3}{|c|}{ PERFILES ESQUEMAS, ESTILOS AFRONTAMIENTO ESQUEMAS Y MODOS DE ESQUEMAS } \\
\hline \multirow{2}{*}{$\begin{array}{l}\text { Esquemas } \\
\text { Predominantes }\end{array}$} & Metas Inalcanzables & $\begin{array}{l}\text { La creencia profunda que uno debe esforzarse por encontrar unos } \\
\text { estándares internos de conducta y rendimientos muy elevados, } \\
\text { normalmente para evitar las críticas. }\end{array}$ \\
\hline & Inhibición emocional & $\begin{array}{l}\text { Excesiva inhibición de la acción espontánea, sentimientos o } \\
\text { comunicación, por lo general para crear un sentimiento de seguridad y } \\
\text { pronóstico; o para evitar cometer errores, la desaprobación de los } \\
\text { demás, catástrofe y caos o la pérdida de control de los propios impulsos. }\end{array}$ \\
\hline \multirow[t]{2}{*}{$\begin{array}{l}\text { Modos } \\
\text { Esquemas }\end{array}$} & Padre Exigente & $\begin{array}{l}\text { Siente que el camino "correcto" es ser perfecto o rendir a un alto nivel, } \\
\text { para mantenerlo todo en orden, se esfuerza por obtener un elevado } \\
\text { estatus, de anteponer sus necesidades a las de los demás, de ser } \\
\text { humillante o de ser eficiente o evitar perder el tiempo. La persona siente } \\
\text { que es erróneo expresar los sentimientos o actuar de forma espontánea. } \\
\text { Este estado de ánimo se refiere a la naturaleza de las normas estrictas y } \\
\text { de las metas elevadas internalizadas, más que al estilo con el que se } \\
\text { aprenden o se aplican; estas reglas no son compensatorias en su } \\
\text { función. }\end{array}$ \\
\hline & Protector Aislado & $\begin{array}{l}\text { Corta, aísla o cerca las necesidades y los sentimientos, se separa } \\
\text { emocionalmente de las personas y rechaza su ayuda, se siente } \\
\text { reservado o introvertido, alejado, distraído, desconcertado o separado, } \\
\text { despersonalizado, vacío o aburrido, sigue distrayéndose, se auto- } \\
\text { tranquiliza o se auto- estimula en actividades ya sea de manera } \\
\text { compulsiva o en exceso. Puede adoptar una postura cínica, reservada o } \\
\text { pesimista para evitar invertir en personas o actividades }\end{array}$ \\
\hline \multicolumn{3}{|r|}{ CURSO DE TRATAMIENTO } \\
\hline \multicolumn{2}{|c|}{$\begin{array}{l}\text { Objetivos Evaluación y } \\
\text { Conceptualización Caso }\end{array}$} & Proceso/ Técnicas \\
\hline \multicolumn{2}{|c|}{ Inicio de la Intervención } & $\begin{array}{l}\text { Permitir su ritmo lento de explicación, no ser demasiado invasivo y no } \\
\text { querer correr. Ser paciente, ayudar a identificar problemas y posibles } \\
\text { esquemas les gusta porqué tiene un componente racional e intelectual. } \\
\text { En algunos casos existen dificultades de etiquetaje de las emociones. }\end{array}$ \\
\hline \multicolumn{2}{|c|}{ Patrones del Pasado } & $\begin{array}{l}\text { Algunas veces son muy prolijos en los detalles y en la manera de } \\
\text { explicar las cosas. Presentan dificultades en explicar el impacto } \\
\text { emocional de las experiencias de vida. }\end{array}$ \\
\hline \multicolumn{2}{|c|}{ Identificación Esquemas } & $\begin{array}{l}\text { En el Cuestionario de Esquemas, en algunos casos como personas muy } \\
\text { ansiosas o con elevada inhibición emocional, se obtienen puntuaciones } \\
\text { bajas en esquemas de autonomía. } \\
\text { Utilización de metáforas y los propios nombres para denominar los } \\
\text { esquemas }\end{array}$ \\
\hline \multicolumn{2}{|c|}{ Activación Esquemas } & $\begin{array}{l}\text { Explicar de manera clara y específica. Manifiestan miedo a experimentar } \\
\text { emociones en sesión. } \\
\text { Si excesiva inhibición de las emociones, utilizar previamente estrategias } \\
\text { tales como la música, películas. }\end{array}$ \\
\hline \multicolumn{2}{|c|}{ Estrategias Afrontamiento } & $\begin{array}{l}\text { Definir las estrategias de mantenimiento y evitación de los esquemas es } \\
\text { de clave. Es importante repasar las estrategias que utilizan para que } \\
\text { observen que son conductas guiadas por el esquema, y no sólo una } \\
\text { conducta de su repertorio conductual }\end{array}$ \\
\hline \multicolumn{2}{|c|}{ Conceptualización } & Esclarecer el tipo de temperamento y de estilo emocional. \\
\hline \multicolumn{2}{|c|}{ Objetivos Cambio Terapéutico } & Procesol Técnicas \\
\hline \multirow{4}{*}{$\begin{array}{c}\text { Metas } \\
\text { Inalcanzables }\end{array}$} & Cognitivo & $\begin{array}{l}\text { Reducir las metas y los estándares irrealistas- utilizar el análisis de los } \\
\text { costes/beneficios } \\
\text { Destacar las ventajas e inconvenientes de las metas tan elevadas, de los } \\
\text { objetivos y estándares inalcanzables: salud, pareja, familia, felicidad, etc. } \\
\text { Reducir el riesgo percibido de hacerlo mal, de "no ser" perfecto. }\end{array}$ \\
\hline & Emocional & $\begin{array}{l}\text { Imaginación: Dialogar con los padres por las altas expectativas. } \\
\text { Desahogar la rabia y la culpa por no estar a la altura de las expectativas } \\
\text { Silla vacia: diálogos entre metas inalcanzables y adulto sano para } \\
\text { encontrar un balance de expectativas a nivel emocional. }\end{array}$ \\
\hline & Relación Terapéutica & $\begin{array}{l}\text { Modelar metas, objetivos y estándares de conducta más equilibrados, } \\
\text { tanto en la terapia como en la propia vida. }\end{array}$ \\
\hline & Conductual & De forma gradual reducir las exigencias, los objetivos no realistas \\
\hline \multirow{4}{*}{$\begin{array}{l}\text { Inhibición } \\
\text { emocional }\end{array}$} & Cognitivo & $\begin{array}{l}\text { Destacar las ventajas de mostrar las emociones. Minimizar las } \\
\text { consecuencias temidas de actuar emocionalmente e impulsivamente. }\end{array}$ \\
\hline & Emocional & $\begin{array}{l}\text { Acceder y expresar las emociones desconocidas en imaginación: cólera, } \\
\text { agresión, sexo, alegría, etc. Dialogar con el padre inhibido. }\end{array}$ \\
\hline & Relación Terapéutica & Modelar y estimular más la expresión de afecto y la espontaneidad. \\
\hline & Conductual & $\begin{array}{l}\text { Discutir y expresar más los sentimientos. Ser más espontáneo. Hacer } \\
\text { actividades como: bailar, sexo, etc. Utilizar tareas graduadas y no } \\
\text { controlar tanto. }\end{array}$ \\
\hline
\end{tabular}


Tabla 18

Guía esquematizada para el Trastorno de la Personalidad Pasivo-Agresivo

Para construir esta guía se tuvieron en cuenta las investigaciones de Sperry (2004) y Arntz (2008)

\begin{tabular}{|c|c|c|}
\hline \multicolumn{3}{|r|}{ PERFILES ESQUEMAS } \\
\hline \multirow[t]{2}{*}{$\begin{array}{l}\text { Esquemas } \\
\text { Predominantes }\end{array}$} & Fracaso & $\begin{array}{l}\text { La creencia que uno ha fracasado, inevitablemente fallará o que } \\
\text { fundamentalmente resulta inadecuado en relación a los grupos de iguales, } \\
\text { en áreas de rendimiento (escuela, carrera, etc.). }\end{array}$ \\
\hline & Desconfianza & $\begin{array}{l}\text { La expectativa que los otros le herirán, abusarán, humillarán, burlarán, } \\
\text { mentirán, manipularán, aprovecharán. }\end{array}$ \\
\hline \multicolumn{3}{|r|}{ CURSO DE TRATAMIENTO } \\
\hline \multicolumn{2}{|c|}{$\begin{array}{l}\text { Objetivos Evaluación y } \\
\text { Conceptualización Caso }\end{array}$} & Proceso / Técnicas \\
\hline \multicolumn{2}{|c|}{ Inicio de la Intervención } & $\begin{array}{l}\text { Ser paciente, la estrategia de unir problemas, emociones y la posible } \\
\text { identificación de los esquemas puede facilitar el hecho de hablar de los } \\
\text { demás. }\end{array}$ \\
\hline \multicolumn{2}{|c|}{ Patrones del Pasado } & $\begin{array}{l}\text { No muestran dificultades en explicar la experiencia del pasado. No } \\
\text { obstante, cuando se hacen señalamientos, resúmenes y reformulaciones } \\
\text { de la experiencia donde se subraye o enfatice la tendencia a "externalizar la } \\
\text { culpa y las responsabilidades a los demás" pueden mostrarse enfadados y } \\
\text { ser considerado una prueba de desconfianza ante el terapeuta. }\end{array}$ \\
\hline \multicolumn{2}{|c|}{ Identificación Esquemas } & $\begin{array}{l}\text { En el Cuestionario de Esquemas, en algunos casos como personas muy } \\
\text { ansiosas o con elevada inhibición emocional, se obtienen puntuaciones } \\
\text { bajas en esquemas de autonomía. Utilización de metáforas y los propios } \\
\text { nombres para denominar los esquemas }\end{array}$ \\
\hline \multicolumn{2}{|c|}{ Activación Esquemas } & $\begin{array}{l}\text { Explicar de manera clara y específica. Manifiestan miedo a experimentar } \\
\text { emociones en sesión, sobretodo rabia. } \\
\mathrm{Si} \text { existen emociones intensas de rabia y culpa, utilizar previamente } \\
\text { estrategias tales como la música, lectura de libros, ver peliculas. }\end{array}$ \\
\hline \multirow{2}{*}{\multicolumn{2}{|c|}{ Estrategias Afrontamiento }} & $\begin{array}{l}\text { Definir el estilo principal de Sobre-compensación. Detallar de manera } \\
\text { específica en que área de la vida utiliza la Manipulación o Explotación } \\
\text { (Encuentra o satisface las necesidades a través de la manipulación } \\
\text { encubierta de los demás, de manera seductora, o deshonestamente), } \\
\text { Pasivo-agresivo y/o Rebelión (Se comporta forma abierta complaciente } \\
\text { mientras castiga a los demás o se rebela de forma encubierta } \\
\text { demorándose, burlándose, retardándose, complaciendo, rebelándose, dejar } \\
\text { de hacer) y Agresión, Hostilidad (Contraataca del siguiente modo: } \\
\text { desafiando, abusando, culpando, atacando o criticando a los demás) }\end{array}$ \\
\hline & & $\begin{array}{l}\text { Esclarecer el papel del temperamento. Dos variables, el balance entre } \\
\text { impulsividad y la susceptibilidad al castigo (inhibición de la conducta ante } \\
\text { estimulos amenazantes) nos dará pistas sobre la probabilidad de perder el } \\
\text { control de la conducta. También hay que detallar antídotos antes iniciar la } \\
\text { fase de cambio para cada una de las estrategias de sobre-compensación } \\
\text { en la relación terapéutica. Establecer los límites de la relación terapéutica } \\
\text { antes del inicio de la intervención. }\end{array}$ \\
\hline \multicolumn{2}{|c|}{ Objetivos Cambio Terapéutico } & Proceso/ Técnicas \\
\hline \multirow{4}{*}{ Fracaso } & Cognitivo & $\begin{array}{l}\text { Retar el punto de vista del paciente que es inherentemente inepto, estúpido. } \\
\text { Reatribución de fracaso a esquema de mantenimiento. Destacar los éxitos y } \\
\text { las habilidades. Fijar expectativas realistas. }\end{array}$ \\
\hline & Emocional & $\begin{array}{l}\text { Acceder a las memorias de los padres, profesores, etc. críticos o de dar } \\
\text { poco soporte. También las comparaciones con los hermanos, o expectativas } \\
\text { poco realistas. Imaginación para vencer la evitación ante situaciones de } \\
\text { "hacer cosas" y "rendimiento". }\end{array}$ \\
\hline & Relación Terapéutica & Apoyar el éxito. Fijar expectativas realistas. Dar estructura, límites. \\
\hline & Conductual & $\begin{array}{l}\text { Graduar tareas para llevar a cabo nuevos retos. Fijar límites, crear } \\
\text { estructuras para vencer la demora y enseñar auto-disciplina. }\end{array}$ \\
\hline \multirow{4}{*}{$\begin{array}{l}\text { Desconfianza } \\
\text { Abuso }\end{array}$} & Cognitivo & $\begin{array}{l}\text { Reducir la "hipervigilancia" de abuso o maltrato. Enseñar el espectro de } \\
\text { desconfianza y maltrato. Tonalidades de gris, en vez de todo o nada. } \\
\text { Cambiar el exagerado punto de vista "acerca de los demás" como } \\
\text { intencionadamente malos, abusivos, manipuladores o deshonestos, y "de } \\
\text { uno mismo" como culpable del abuso o de estar indefenso ante el abuso. } \\
\text { No excusar al abusador. }\end{array}$ \\
\hline & Emocional & $\begin{array}{l}\text { Recuperar memorias de desconfianza, humillación u abuso. Expresar rabia } \\
\text { verbalmente y físicamente, en imaginación. Escribir cartas necesidades } \\
\text { emocionales no cubiertas. No enviar las cartas! }\end{array}$ \\
\hline & $\begin{array}{l}\text { Relación } \\
\text { Terapéutica }\end{array}$ & $\begin{array}{l}\text { Ser completamente honesto y genuino con el paciente. Preguntar por la } \\
\text { confianza e intimidad de forma regular - discutir cualquier sentimiento } \\
\text { negativo hacia el terapeuta. Preguntar acerca de la vigilancia ("necesidad } \\
\text { de control") en las sesiones. Si es necesario no hacer trabajo experiencial, } \\
\text { mientras se esté construyendo la confianza. }\end{array}$ \\
\hline & Conductual & $\begin{array}{l}\text { Necesitarán soporte de otros profesionales, en función del déficit funcional. } \\
\text { Esto les ayudará a confiar en las personas. Aprendizaje del Manejo de } \\
\text { emociones (rabia, disforia, ansiedad) y de Habilidades Sociales. Dar } \\
\text { oportunidades de relación (amistad, pareja) que son confiables. Cambiar las } \\
\text { conductas extravagantes, mediante modelado de conducta. }\end{array}$ \\
\hline
\end{tabular}


Tabla 19

Guía esquematizada para el Trastorno de la Personalidad Depresivo

Para construir esta guía se tuvieron en cuenta las investigaciones de Arntz y Van Genderen (2009), Ball y Cecero (2001) y Arntz (2008)

\begin{tabular}{|c|c|c|c|}
\hline \multicolumn{4}{|c|}{ PERFILES ESQUEMAS, ESTILOS AFRONTAMIENTO ESQUEMAS Y MODOS DE ESQUEMAS } \\
\hline \multirow{6}{*}{$\begin{array}{l}\text { Esquemas } \\
\text { Predominantes }\end{array}$} & \multicolumn{2}{|c|}{ Desconfianza } & $\begin{array}{l}\text { Expectativa que los otros le herirán, abusarán, humillarán, burlarán, } \\
\text { mentirán, manipularán, aprovecharán }\end{array}$ \\
\hline & \multicolumn{2}{|c|}{$\begin{array}{l}\text { Aislamiento } \\
\text { Social }\end{array}$} & $\begin{array}{l}\text { El sentimiento de que está aislado del resto del mundo, diferente de los } \\
\text { demás y no forma parte de un grupo. }\end{array}$ \\
\hline & \multicolumn{2}{|c|}{ Imperfección } & $\begin{array}{l}\text { Sentimiento de que es defectuoso, malo, no querido, inferior o inválido en } \\
\text { aspectos importantes; o que uno sería no querido de forma significativa } \\
\text { por los demás si se muestra tal como es }\end{array}$ \\
\hline & \multicolumn{2}{|c|}{ Fracaso } & $\begin{array}{l}\text { La creencia que uno ha fracasado, inevitablemente fallará o que } \\
\text { fundamentalmente resulta inadecuado en relación a los grupos de iguales, } \\
\text { en áreas de rendimiento (escuela, carrera, etc.). }\end{array}$ \\
\hline & \multicolumn{2}{|c|}{$\begin{array}{l}\text { Vulnerabilidad } \\
\text { al peligro }\end{array}$} & $\begin{array}{l}\text { Miedo exagerado a que una "fortuita/azarosa" catástrofe podría ocurrir en } \\
\text { cualquier momento y que no será capaz de prevenirla. }\end{array}$ \\
\hline & \multicolumn{2}{|c|}{ Subyugación } & $\begin{array}{l}\text { Excesivamente entregados o abandonados al control de los demás porque } \\
\text { uno se siente cohesionado: usualmente para evitar represalias o abandono }\end{array}$ \\
\hline \multicolumn{4}{|r|}{ CURSO DE TRATAMIENTO } \\
\hline \multicolumn{2}{|c|}{ Objetivos Conceptualización } & \multicolumn{2}{|r|}{ Procesol Técnicas } \\
\hline \multicolumn{2}{|c|}{ Inicio de la Intervención } & \multicolumn{2}{|c|}{$\begin{array}{l}\text { Delimitar problemas de autonomía y en las relaciones. Empatizar con el estado de } \\
\text { ánimo e identificar los desencadenantes y los contextos donde se producen. }\end{array}$} \\
\hline \multicolumn{2}{|c|}{ Patrones del Pasado } & \multicolumn{2}{|c|}{$\begin{array}{l}\text { Delimitar situaciones donde se daban las emociones de tristeza, estado de ánimo bajo, } \\
\text { enfado, humillación, rabia y culpa. Identificar posibles modelos de conducta (pasado) } \\
\text { Ajustar las reformulaciones a las palabras del paciente. }\end{array}$} \\
\hline \multicolumn{2}{|c|}{ Identificación Esquemas } & \multicolumn{2}{|c|}{$\begin{array}{l}\text { Administración de cuestionarios para delimitar los esquemas. Si el ánimo está triste } \\
\text { habrá mayores puntuaciones en algunos esquemas de la dimensión separación } \\
\text { rechazo. Utilizar metáforas en la devolución. }\end{array}$} \\
\hline \multicolumn{2}{|c|}{ Activación Esquemas } & \multicolumn{2}{|c|}{$\begin{array}{l}\text { Explicar de manera clara. Manifiestan miedo a experimentar emociones en sesión. Ante } \\
\text { excesivo pesimismo dejar para más adelante la imaginación. }\end{array}$} \\
\hline \multicolumn{2}{|c|}{ Estrategias Afrontamiento } & \multicolumn{2}{|c|}{$\begin{array}{l}\text { Identificar las estrategias de evitación y de mantenimiento de los esquemas. Definir el } \\
\text { déficit de habilidades en las relaciones sociales y intimas. }\end{array}$} \\
\hline \multicolumn{2}{|c|}{ Conceptualización } & \multicolumn{2}{|c|}{ Delimitar el tipo de temperamento, y como se da labilidad emocional. } \\
\hline \multicolumn{2}{|c|}{ Objetivos Cambio Terapéutico } & \multicolumn{2}{|r|}{ Proceso/ Técnicas } \\
\hline \multirow{4}{*}{$\begin{array}{l}\text { Desconfianza } \\
\text { Abuso }\end{array}$} & Cognitivo & \multicolumn{2}{|c|}{$\begin{array}{l}\text { Cambiar el punto de vista "acerca de los demás" como intencionadamente malos, } \\
\text { abusivos, manipuladores o deshonestos, y "de uno mismo" como culpable del abuso o } \\
\text { de estar indefenso ante el abuso. No excusar al abusador. }\end{array}$} \\
\hline & Emocional & \multicolumn{2}{|c|}{$\begin{array}{l}\text { Recuperar memorias de desconfianza, humillación u abuso. Expresar rabia verbalmente } \\
\text { y fisicamente, en imaginación. Escribir cartas necesidades emocionales no cubiertas. } \\
\text { No enviar las cartas. }\end{array}$} \\
\hline & $\begin{array}{c}\text { Relación } \\
\text { Terapéutica }\end{array}$ & \multicolumn{2}{|c|}{$\begin{array}{l}\text { Ser completamente honesto y genuino con el paciente. Preguntar por la confianza, } \\
\text { intimidad y vigilancia de forma regular, discutir cualquier sentimiento negativo hacia el } \\
\text { terapeuta. Si es necesario no hacer, en principio, trabajo experiencial. }\end{array}$} \\
\hline & Conductual & \multicolumn{2}{|c|}{$\begin{array}{l}\text { Aprendizaje del Manejo de emociones (rabia, disforia, ansiedad) y de Habilidades } \\
\text { Sociales. Dar oportunidades de relación (amistad, pareja) que son confiables. }\end{array}$} \\
\hline & Cognitivo & \multicolumn{2}{|c|}{$\begin{array}{l}\text { Cambiar punto de vista de que es indeseable socialmente. Cambiar el exagerado punto } \\
\text { de vista negativo respecto a la apariencia y las habilidades sociales. }\end{array}$} \\
\hline & Emocional & $\begin{array}{l}\text { Imag } \\
\text { Vent } \\
\text { acep }\end{array}$ & $\begin{array}{l}\text { n de memorias de ser diferente a los demás, rechazo, o aislamiento. } \\
\text { nociones negativas hacia el grupo. Recuperar recuerdos donde se sentía } \\
\text { había contacto social para reforzar cambio. }\end{array}$ \\
\hline social & $\begin{array}{l}\text { Relación } \\
\text { Terapéutica }\end{array}$ & $\begin{array}{l}\text { Estar } \\
\text { difere } \\
\text { socia }\end{array}$ & $\begin{array}{l}\text { o a las situaciones dentro de la sesión en las que el paciente se pueda sentir } \\
\text { inferior o abrumado por la energía del terapeuta. Enfatizar los atributos } \\
\text { sitivos y confrontar la evitación de las situaciones sociales. }\end{array}$ \\
\hline & Conductual & $\begin{array}{l}\text { Venc } \\
\text { Habil }\end{array}$ & $\begin{array}{l}\text { vitación: Listar las situaciones temidas y que se evitan. Aprendizaje de } \\
\text { que faciliten la Competencia Social. Valorar Terapia Grupo. }\end{array}$ \\
\hline & Cognitivo & $\begin{array}{l}\text { Reta } \\
\text { Reat } \\
\text { Fijar }\end{array}$ & $\begin{array}{l}\text { Into de vista del paciente que es inherentemente inepto, estúpido. } \\
\text { on de fracaso a esquema de mantenimiento. Destacar éxitos y habilidades. } \\
\text { tativas realistas. }\end{array}$ \\
\hline Fracaso & Emocional & $\begin{array}{l}\text { Acce } \\
\text { Tamt } \\
\text { Imag }\end{array}$ & $\begin{array}{l}\text { las memorias de los padres, profesores, etc. críticos o de dar poco soporte. } \\
\text { las comparaciones con los hermanos o expectativas poco realistas. } \\
\text { n para vencer la evitación ante situaciones de "hacer cosas" y "rendimiento". }\end{array}$ \\
\hline & $\begin{array}{c}\text { Relación } \\
\text { Terapéutica }\end{array}$ & Apoy & Exito. Dar estructura, límites. Fijar expectativas realistas \\
\hline & Conductual & $\begin{array}{l}\text { Grad } \\
\text { venc }\end{array}$ & $\begin{array}{l}\text { as para llevar a cabo nuevos retos. Fijar límites, crear estructuras para } \\
\text { nora y enseñar auto-disciplina. }\end{array}$ \\
\hline & Cognitivo & Reta & xageradas consecuencias negativas de expresar las necesidades \\
\hline & Emocional & Expr & ólera y afirmar los derechos al padre controlador a través de la imaginación. \\
\hline Subyugación & $\begin{array}{c}\text { Relación } \\
\text { Terapéutica }\end{array}$ & $\begin{array}{l}\text { No c } \\
\text { respe }\end{array}$ & $\begin{array}{l}\text { ar en exceso. Estimular al paciente a tomar decisiones. Señalar la conducta } \\
\text { l- identificando la cólera. }\end{array}$ \\
\hline & Conductual & $\begin{array}{l}\text { Sele } \\
\text { afirm } \\
\text { actua }\end{array}$ & $\begin{array}{l}\text { Ir compañeros que no sean controladores. Gradualmente hacer valer o } \\
\text { "propias" necesidades ante los demás. Aprender las inclinaciones naturales y } \\
\text { un ellas. }\end{array}$ \\
\hline
\end{tabular}




\section{CONCLUSIONES}

En síntesis, son muchas las razones por las que son dificultosos los abordajes psicológicos para los Trastornos de la personalidad. La dificultad de protocololarización es sólo una de ellas. Los aportes de Young, Klosko y Wheishar constituyen sin duda una propuesta teórica, con desarrollo de tecnología -tanto para la evaluación como para la intervención- para la praxis clínica con este tipo de pacientes.

La Terapia de esquemas es un tratamiento que partiendo de una conceptualización de caso brinda el sustento para determinar objetivos realistas y dispone de un bagaje de intervenciones para alcanzarlos. En este sentido las 'Guías esquematizadas para profesionales' están diseñadas para facilitar la tarea de terapeuta y constituyen un humilde aporte para facilitar la aplicación de la misma.

Es importante aclarar que tanto los trabajos de Tineo y Young (2006) y Tineo, Alén, Chajét, Chajét y Sá (2006); como los de Cid y Torrubia (2003), Cid (2009) y Cid, Tejero y Torrubia (1997) son un gran aporte a la difusión y desarrollo de la Terapia de esquemas en lengua hispana y nos apoyamos en ellos para la realización de esta propuesta.

\section{REFERENCIAS}

Addington, J. \& Tran, L. (2009). Using the Brief Core Schema Scales with Individuals at Clinical High Risk of Psychosis. Behavioral and Cognitive Therapy. 37 (2),227-231.

Alford, B. \& Beck, A.T. (1997). The Integrative Power of Cognitive Therapy. New York: Guilford Press.

American Psychiatric Association (2002). DSM-IV-TR: Manual diagnóstico y estadístico de los trastornos mentales (Texto revisado). Barcelona: Masson.

Arntz, A. \& van Genderen, H. (2009). Schema Therapy of Borderline Personality Disorder. Chichester: Wiley.

Arntz, A. (2008). Schema-focused therapy for borderline personality disorder: effectiveness and cost-effectiveness, evidence from a multicenter trial. European Psychiatry, 23 (2),65-66.

Ball, S.A. \& Cecero, J.J. (2001). Addicted patients with personality disorders: Traits, schemas, and presenting problems. Journal of Personality Disorders, 15 (1),72-83.

Baranoff, J., Oei, T., Seong, H.C. \& Seok-Man, K. (2006). Factor structura and internal consistency of the Young Schema Questionnaire (Short Form) in Korean and Ausltralian samples. ISAD, 93 (1),133-140.

Beck, A.T. (1996). Beyond belief: A theory of modes, personality, and psychopathology. En P. Salkovskis (Ed),
Frontiers of Cognitive Therapy (pp. 1-25). New York: Guilford Press.

Beck, A.T., Freeman, A., Davis, D.D. y otros (2005). Terapia cognitiva de los trastornos de personalidad. Buenos Aires: Paidós Ibérica.

Behary, W.T. (2008). Disarming the narcissist: surviving \& thriving with the self-absorbed. Oakland, CA: New Harbinger Publications.

Bernstein, D.P. (2002). Cognitive therapy of Personality Disorders in Patients with histories of Emocional Abuse or Neglect. Psychiatric Annals, 32 (10),618-628.

Blatner, A. \& Blatner, A. (1988). Foundations of Psychodrama. History, Theory, \& Practice. ( $3^{\circ}$ edición). New York: Springer Publishing Company.

Blatner, A. (1996). Acting-in. Practical Applications of Psychodramatic Methods. ( $3^{\circ}$ edición). New York: Springer Publishig Company.

Cid J. \& Torrubia R. (2003). What are the clinical meaning and implications for treatment of the schemas assessment using the Schema Questionnaire?. Revue Francophone de clinique comportementale et cognitive, 8 (1),15-25.

Cid, J. (2009). La Terapia de Esquemas. En: L. Fernández de la Cruz L, M.A. Fullana \& O. Andión. Actualizaciones de la Societat Catalana de Recerca i Teràpia del Comportament.

Cid, J., Tejero, A., \& Torrubia, R. (1997). Adaptación española del Cuestionario de Esquemas de Young (Spanish version of the Young Schema Questionnaire). Manuscrito no publicado.

French, P. \& Morrison, A.P. (2004). Early Detection and Cognitive Therapy for People at High Risk of Developing Psychosis: A Treatment approach. New York: John Wiley.

Giesen-Bloo J., van Dyck R., Spinhoven P., van Tilburg W., Dirksen C., van Asselt T., Kremers I., Nadort M., \& Arntz A. (2006). One-Year Follow-up of Schema focused therapy and Transference focused psychotherapy for $B P D$, and the influence of drop-out status, treatment status and medication. Crossing Borders: Theory, Assessment and Treatment in Borderline Personality Disorder, 127-142.

Giesen-Bloo J., van Dyck R., Spinhoven P., van Tilburg W., Dirksen C., van Asselt T., Kremers I., Nadort M. \& Arntz A. (2006). Outpatient psychotherapy for borderline personality disorder: randomized trial of schema-focused therapy vs transference-focused psychotherapy. Arch Gen Psychiatry, 63 (9),649-658.

Gouveia, V.V., Chaves, S.S.S., Oliveira, I P., Dias, M.R., Gouveia, R.S.V., \& Andrade, P.R. (2003). A utilização do QSG-12 na população geral: Estudo de sua validade de construto. Psicologia: Teoria e Pesquisa, 19 (13), 241-248.

Gude, T., Hoffart, A., Hedley, L., \& Rø, Ø. (2004). The dimensionality of dependent personality disorder. Journal of Personality Disorders, 18,(6),604-610.

Kepner, J. (1987). Proceso corporal: Un enfoque Gestalt para el trabajo corporal en psicoterapia. México: El Manual Moderno. 
Lapierre, A. \& Aucouturier, B. (1990) El cuerpo y el Incosnciente en Educación y Terapia. México: Científico-Médica.

Lobbestael, J., Vreeswijk, M. F. van, \& Arntz, A. (2008). An empirical test of schema mode conceptualisations in personality disorders. Behaviour Research and Therapy, 46 (7),854-860.

Lobbestael, J., Vreeswijk, M.F. van, \&Arntz, A. (2007). Shedding light on schema modes: a clarification of the mode concept and its current research status. Netherlands Journal of Psychology, 63 (3),69-78.

Loper, A.B. (2003). The relationship of maladaptive beliefs to personality and behavioral adjustment among incarcerated women. Journal of Cognitive Psychotherapy, 17 (3),253-266.

López Pell, A.F., Rondón, J.M., Cellerino, C. \& Alfano, S.M. (2010). Guías esquematizadas de tratamiento de los Trastornos de la personalidad para profesionales, desde el modelo de Beck, Freeman, Davis y otros (2005). Revista Ciencias Psicológicas, 4 (1),97-124.

López Pell, A.F., Rondón, J.M., Alfano, S.M. \& Cellerino, C. (2010). Guías esquematizadas de tratamiento de los Trastornos de la personalidad para profesionales, desde el modelo de Theodore Millon. Revista Ciencias Psicológicas, 4 (2),239-271.

Nadort, M., Arntz, A., Smit, J.H., Giesen-Bloo, J., Eikelenboom, M., Spinhoven, P., van Asselt, T., Wending, M. \& van Dyck, R. (2009). Implementation of outpatient schema therapy for borderline personality disorder with versus without crisis support by the therapist outside office hours: A randomized trial. Behaviour Research and Therapy, 47 (11),961-973.

Nadort, M., van Dyck, R., Smit, J.H., Giesen-Bloo, J., Eikelenboom, M., Wensing, M., Spinhoven, P., Dirksen, C., Bleecke, J., van Milligen, B., van Vreeswijk, M. \& Arntz, A. (2009). Three preparatory studies for promoting implementation of outpatient schema therapy for borderline personality disorder in general mental health care. Behaviour Research and Therapy, 47 (11), 938-945

Obst Camerini, J. (2000). El Psicodrama Cognitivo Conductual. Bs. As.: CATREC.

Obst Camerini, J. (2008). La Terapia Cognitiva. Integrada y actualizada. Buenos Aires: CATREC.

. Rijkeboer, M. M., van den Bergh, H. \& van den Bout, J. (2005). Stability and discriminative power of the Young Schema-Questionnaire in a Dutch clinical versus non- clinical population. Journal of Behavior Therapy and Experimental Psychiatry, 36 (2),129-144.

Simos, G. (2002). Cognitive Behavior Therapy: A Guide for the Practicing Clinician, East Sussex: BrunnerRoutledge. Philadelphia, PA: Taylor \& Francis.

Sperry, L. (2006). Cognitive behavior therapy of DSM-IV-TR personality disorders: Highly effective interventions for the most common personality disorders (Second edition). New York: Routledge.

Tineo, Lydia (1997). El proceso terapéutico en la terapia centrada en esquemas. En Caro, Isabel (1997) . Manual de Psicoterapias Cognitivas. Barcelona: Paidós.

Tineo, Lydia (2008). Trastorno Borderline. Revista de la Asociación de Psicoterapia de la República Argentina, Año 1 (2) .

Young, J. \& Brown, G. (2001). Young Schema Questionnaire. New York: Schema Therapy Institute.

Young, J. \& Klosko, J. (2007). Terapia de esquemas. En J.M. Oldham, A.E. Skodol \& D.S. Bender (Eds), Tratado de los trastornos de la personalidad (pp. 289-308). Barcelona: Elsevier Masson.

Young, J. \& Ryght, J. (1994). Young-Ryght Avoidance Inventory. New York: Cognitive Therapy Center of New York.

Young, J. (1990). Cognitive therapy for personality disorders: a schema -focused approach. Sarasota-. Fl.: Professional Resource Exchange, Inc.

Young, J. (1993). The Schema Diary. New York: Cognitive Therapy Center of New York.

Young, J. (1994a). Cognitive Therapy for Personality Disorders: A Schema Focused Approach (Revised Edition). Sarasota, FL: Professional Resource Exchange.

Young, J. (1994b). Young Parenting Inventory. New York: Schema Therapy Institute.

Young, J. (1995). Young Compensation Inventory. New York: Cognitive Therapy Center of New York.

Young, J. (1999). Cognitive therapy for personality disorders: A schema focused approach (3 ed.). Sarasota, FL: Professional Resource Press.

Young, J., Klosko, J. \& Weishaar, M. (2003). Schema Therapy. A Practitioner's Guide. New York: Guilford Press.

Young, J., Wattenmaker, D. \& Wattenmaker, R. (1996). Schema Therapy Flashcard. New York: Cognitive Therapy Center of New York.

Para citar este artículo:

López Pell, A.F., Cid Colom, J., Obst Camerini, J., Rondón, J. M., Alfano, S. M. \& Cellerino, C. (2011). Guías esquematizadas de tratamiento de los trastornos de personalidad para profesionales, desde el modelo de Young, Klosko y Wheishar (2003). Ciencias Psicológicas V (1): 83-115. 